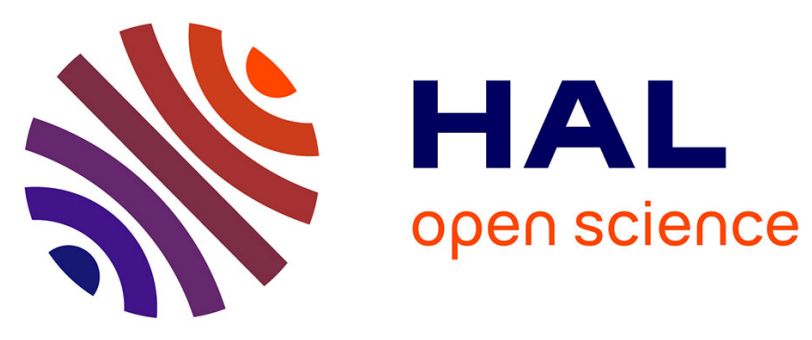

\title{
Design, synthesis, and biological evaluation of dual targeting inhibitors of histone deacetylase $6 / 8$ and bromodomain BRPF1
}

Ehab Ghazy, Patrik Zeyen, Daniel Herp, Martin Hügle, Karin Schmidtkunz, Frank Erdmann, Dina Robaa, Matthias Schmidt, Elizabeth Morales,

Christophe Romier, et al.

\section{To cite this version:}

Ehab Ghazy, Patrik Zeyen, Daniel Herp, Martin Hügle, Karin Schmidtkunz, et al.. Design, synthesis, and biological evaluation of dual targeting inhibitors of histone deacetylase $6 / 8$ and bromodomain BRPF1. European Journal of Medicinal Chemistry, 2020, 200, pp.112338. 10.1016/j.ejmech.2020.112338 . hal-02999300

\section{HAL Id: hal-02999300 https://hal.science/hal-02999300}

Submitted on 27 Nov 2020

HAL is a multi-disciplinary open access archive for the deposit and dissemination of scientific research documents, whether they are published or not. The documents may come from teaching and research institutions in France or abroad, or from public or private research centers.
L'archive ouverte pluridisciplinaire $\mathbf{H A L}$, est destinée au dépôt et à la diffusion de documents scientifiques de niveau recherche, publiés ou non, émanant des établissements d'enseignement et de recherche français ou étrangers, des laboratoires publics ou privés. 


\title{
Design, synthesis, and biological evaluation of dual targeting inhibitors of histone deacetylase 6/8 and bromodomain BRPF1
}

Ehab Ghazy $^{\mathrm{a}}$; Patrik Zeyen ${ }^{\mathrm{a}}$ Daniel Herp ${ }^{\mathrm{b}}$; Martin Hügle ${ }^{\mathrm{b}}$; Karin Schmidtkunz ${ }^{\mathrm{b}}$; Frank Erdmann ${ }^{\mathrm{a}}$; Dina Robaa ${ }^{\mathrm{a}}$; Matthias Schmidt ${ }^{\mathrm{a}}$; Elizabeth R. Morales ${ }^{\mathrm{c}}$; Christophe Romier ${ }^{\mathrm{c}}$; Stefan Günther ${ }^{\mathrm{b}}$; Manfred Jung ${ }^{b}$; Wolfgang Sippl ${ }^{\text {a }}$

${ }^{a}$ Institute of Pharmacy, Martin-Luther University of Halle-Wittenberg, 06120 Halle/Saale, Germany

${ }^{b}$ Institute of Pharmaceutical Sciences, University of Freiburg, 79104 Freiburg, Germany

${ }^{c}$ Département de Biologie Structurale Intégrative, Institut de Génétique et Biologie Moléculaire et Cellulaire (IGBMC), Université de Strasbourg, CNRS, INSERM, 67404 Illkirch Cedex, France

\section{Corresponding author: Wolfgang Sippl}

Wolfgang.sippl@pharmazie.uni-halle.de

Wolfgang-Langenbeck-Str. 4, 06120 Halle (Saale)

\begin{abstract}
Histone modifying proteins, specifically histone deacetylases (HDACs) and bromodomains, have emerged as novel promising targets for anticancer therapy. In the current work, based on available crystal structures and docking studies, we designed dual inhibitors of both HDAC6/8 and the bromodomain and PHD finger containing protein 1 (BRPF1). Biochemical and biophysical tests showed that compounds 23a,b and 37 are nanomolar inhibitors of both target proteins. Detailed structure-activity relationships were deduced for the synthesized inhibitors which were supported by extensive docking and molecular dynamics studies. Cellular testing in acute myeloid leukemia (AML) cells showed only a weak effect, most probably because of the poor permeability of the inhibitors. We also aimed to analyse the target engagement and the cellular activity of the novel inhibitors by determining the protein acetylation levels in cells by western blotting (tubulin vs histone acetylation), and by assessing their effects on various cancer cell lines.
\end{abstract}

\section{Keywords}

Epigenetics, dual targeting inhibitors, HDAC6, HDAC8, bromodomain, BRPF1, hydroxamic acids, acute myeloid leukemia. 


\section{$\underline{\text { 1. Introduction }}$}

Post-translational modifications (PTMs) of histones, along with DNA methylation, are the most extensively studied pathways of epigenetic control of gene expression [1]. Histones are subject to various PTMs that include acylation, acetylation, methylation, phosphorylation, and ubiquitination. Acetylation of lysine residues of histones is a dynamic process which results in opening up the chromatin structure. This leads to an increase in the accessibility of the DNA by the transcription machinery and is usually associated with increased gene expression [2-4]. The state of histone acetylation is controlled by different regulators, namely writer proteins; (histone acetyltransferases (HATs)), reader proteins; (bromodomains (BRDs)), and eraser proteins; (histone deacetylases (HDACs)). Deregulation of these key players, and consequently abnormal acetylation levels, is linked to several pathologies such as inflammatory, metabolic, and cardiovascular diseases, and more clearly cancer [5-10].

Bromodomains usually occur as an integral part of larger protein complexes. Due to their ability to specifically recognize $\varepsilon-N$-acetylated lysine residues, they are generally responsible - together with other epigenetic readers - for the recruitment of transcription factors to chromatin. The human proteome contains 61 bromodomains, which are present within 46 different proteins and are classified into eight distinct families [11, 12]. Due to their relation to different malignancies and their druggability, they have emerged as promising targets for anticancer therapy. Many inhibitors showed notable potency and selectivity in biochemical and biophysical assays against different bromodomain classes, together with significant in vitro activity against various tumor cell lines (reviewed in $[13,14]$ ). The bromodomain and PHD finger containing protein (BRPF) family has recently received increasing interest to elucidate its physiological role and pathological functions. BRPFs have multiple reader domains, including a bromodomain, and act as a scaffold for the recruitment and assembly of the histone acetyltransferases of the MYST family. Normal activity of these HATs is essential for different physiological processes, whereas their deregulation is associated with overexpression of oncogenes and development of different tumors, more notably leukemia [15-17]. Several BRPF inhibitors containing a 1,3-dimethyl benzimidazolone scaffold were reported (Figure 1; compound I), which not only showed high potency and selectivity against the BRPF family, but in some cases also subtype selectivity for BRPF1 [18, 19]. This scaffold was also utilized to design dual targeting inhibitors of BRPF1 and the transcription factor TRIM24 (e.g. compound II, Figure 1) as well as dual inhibitors of BRPF and other bromodomains [20-23]. Another group reported a pan BRPF inhibitor containing a 1,3-dimethylquinolin-2-one scaffold (e.g. compound III; Figure 1) that showed low nanomolar potency against BRPFs and excellent selectivity [24, 25]. Recently, a hit-to-lead campaign identified a 1,4-dimethyl-2,3-dioxoquinoxaline (e.g. compound IV; Figure 1) and 2,4-dimethyloxazole derivatives as low micromolar probes for BRPF1 with good selectivity [26, 27]. 

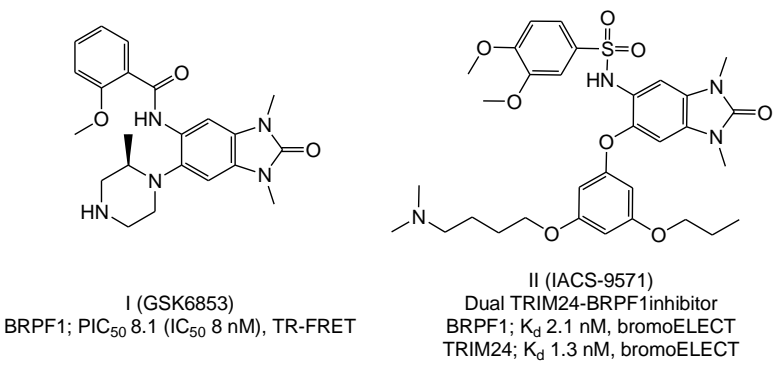

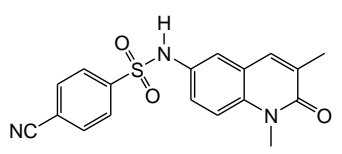

III (NI-57)
BRPF1; $\mathrm{K}_{\mathrm{d}} 40 \mathrm{nM}$, ITC

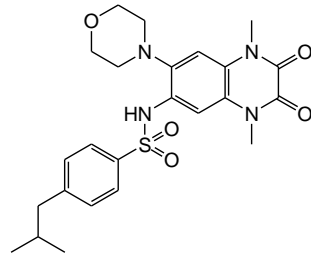

BRPF1; $\mathrm{K}_{\mathrm{d}} 1.8 \mu \mathrm{M}$, Bromoscan

BRPF1 inhibitors

Figure 1: Examples of previously reported BRPF bromodomain inhibitors

HDACs are a group of enzymes responsible for the removal of acyl groups from acylated lysine residues in histones and non-histone proteins. HDACs comprise 18 isoforms categorized into 4 classes differing in size, cellular distribution, substrate, and mechanism of catalytic activity. The deacetylase activity of classical HDACs (class I, II and IV) is mediated through zinc ion, while sirtuins (class III) depend on nicotinamide adenine dinucleotide $\left(\mathrm{NAD}^{+}\right)$for their action $[28,29]$. Given the large variation of their substrates, HDACs regulate diverse physiological processes, in addition to their epigenetic role. Their aberrant activity is linked to different pathologies such as cardiac hypertrophy [30, 31], neurodegenerative diseases [32, 33], viral infections [34, 35], and cancer [36, 37]. As a result, a lot of effort has been devoted to the development of HDAC inhibitors (HDACi) to fully reveal their physiological role. This work has already resulted in a large number of promising probes and some candidates in clinical trials (either as single agents or in combination therapy). Four drugs for the treatment of specific hematological malignancies have been approved by the FDA [38]. However, currently FDA approved drugs are pan HDAC inhibitors, with several side effects such as cardiotoxicity. This necessitates the design of selective HDAC inhibitors for disease-related isoforms [39-41].

The quest for selective HDAC6 and 8 inhibitors is of high importance given their specific role in different disorders and limited side effects that oberved from their inhibition or knockdown studies. HDAC6 is a class IIb isoform that localizes in the cytoplasm, and deacetylates mainly non-histone proteins including a-tubulin, cortactin and heat-shock protein 90 (Hsp90) [42, 43]. Over the last decade, a variety of HDAC6 selective inhibitors (in vitro) were reported ([44-50] and reviewed [51]) showing nanomolar inhibitory activity, good in vitro selectivity over other isoforms in biochemical assays (Figure 2), and some also exhibited promising in vitro activity against various cancer cell lines. Additionally HDAC6 deregulation is associated with different neurodegenerative disorders, inflammatory and rare diseases [52-55], and its selective inhibitors could represent a valuable tool to study the mechanisms underlying these diseases and/or a potential therapeutic tool to treat them. Recently published studies have however shown that selective HDAC6 inhibition in cells is not sufficient for an anti-cancer effect and that the observed anti-cancer effect of reported HDAC6 inhibitors might be the result of inhibiting other HDACs or other off-targets [56, 57]. Class I member HDAC8 localizes to either the nucleus or the cytoplasm, and therefore can interact with non-histone proteins such as cortactin, SMC3, ERR $\alpha$ and p53. HDAC8 is associated with a wide variety of tumors, and recent evidence suggests a potential therapeutic benefit from its inhibition $[58,59]$. Recent research also revealed some unique structural features in this isoform, which distinguish it from other HDACs and which can be utilized to design selective inhibitors [60]. As a result, a variety of probes emerged (Figure 3) that showed preferential in vitro inhibition of HDAC8 compared to other isoforms ([61-66], reviewed in [67, 68]). 
<smiles>COc1ccc(N(C)c2nc(C)nc3ccccc23)cc1OCCCC(=O)NO</smiles><smiles>O=C(/C=C/c1cccc(S(=O)(=O)n2ccc3cccnc32)c1)NO</smiles>

$\mathrm{VI}$
HDAC6; IC
50 $5.2 \mathrm{nM}$,

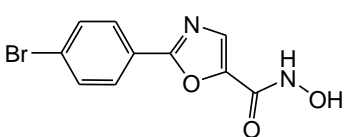

VII
HDAC6; IC
50 $59 \mathrm{nM}$,

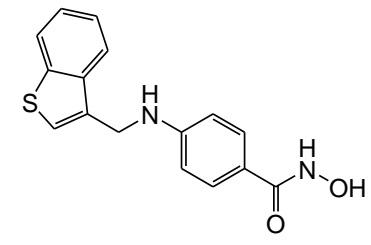

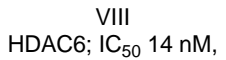<smiles>O=C(Cc1ccc(C(=O)NO)cc1)NC1CC(=O)c2ccccc2C1=O</smiles>
IX HDAC6; $1 \mathrm{I}_{50} 6 \mathrm{nM}$,



HDAC6; IC 15 nM

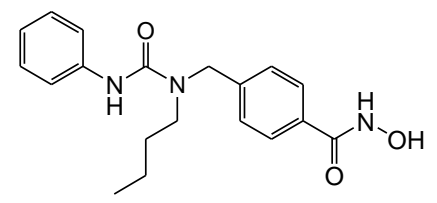

XI (Nexturastat A)

Figure 2: Examples of previously reported HDAC6 inhibitors.

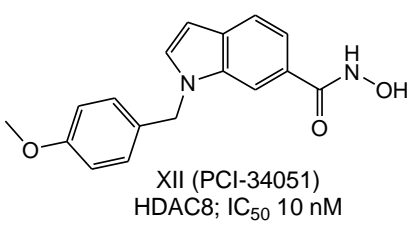

HDAC8; $\mathrm{IC}_{50} 10 \mathrm{nM}$

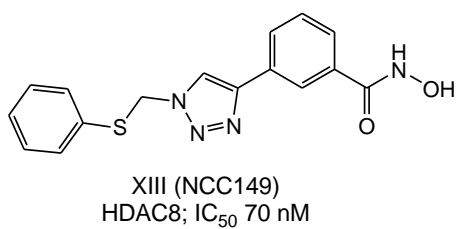

HDAC8; $\mathrm{IC}_{50} 70 \mathrm{nM}$<smiles>COc1ccc(C(=O)NO)cc1OCc1ccccc1</smiles>

XIV

HDAC8; IC $5027 \mathrm{nM}$
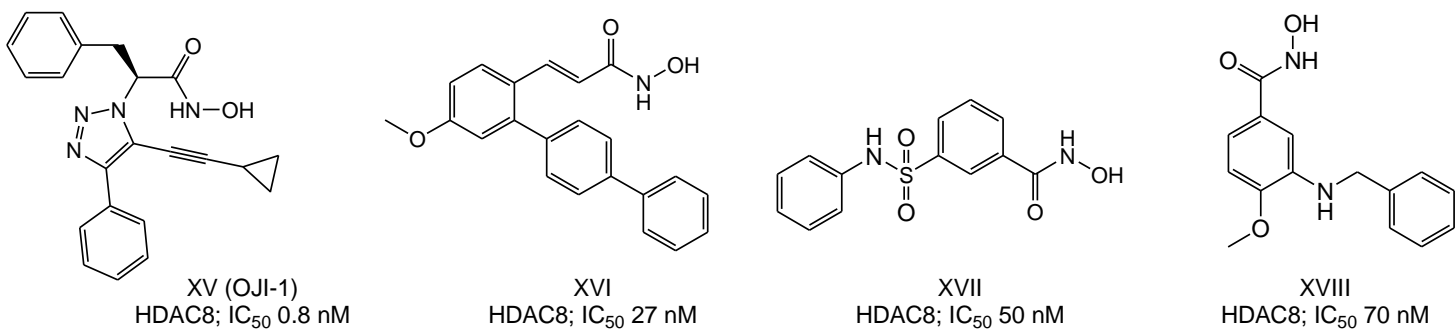

XVIII
HDAC8; IC
50 $70 \mathrm{nM}$

Figure 3: Examples of previously reported HDAC8 inhibitors

Several studies suggest that combination therapies of epigenetic modulators could achieve better clinical results than a monotherapy, especially against solid and resistant tumors (reviewed in [69]). As a result, the polypharmacology concept was extended to the epigenetics field, assuming that a multi-target inhibitor could be more effective than single agents. Moreover, such an inhibitor is postulated to show higher therapeutic efficacy, better predictable pharmacokinetic profile, and improved patient compliance as compared to a combination therapy. In this context, several dual acting HDACi were designed to interact with a second target such as kinases, metalloproteinases, topoisomerases, and others (reviewed in details in [70]). Bromodomains received also some interest in this regard, as some dual bromodomain/kinase inhibitors were investigated [71-74]. Of particular relevance to the current work are the attempts to design dual HDAC/BRD epigenetic inhibitors [75-79]. In all of the reported studies, the rationale was to change the cap group of HDACi, mostly SAHA, to a reported BRD4 inhibiting pharmacophore. Indeed, the authors were not only able to achieve dual inhibitory activity for some compounds (Figure 4), but also promising in vitro activity against some cancer cell lines. However, the results failed to show superior activity 
over the original HDAC or BRD inhibitors. Additionally, little information was given regarding the selectivity of these dual inhibitors on different HDAC isoforms.
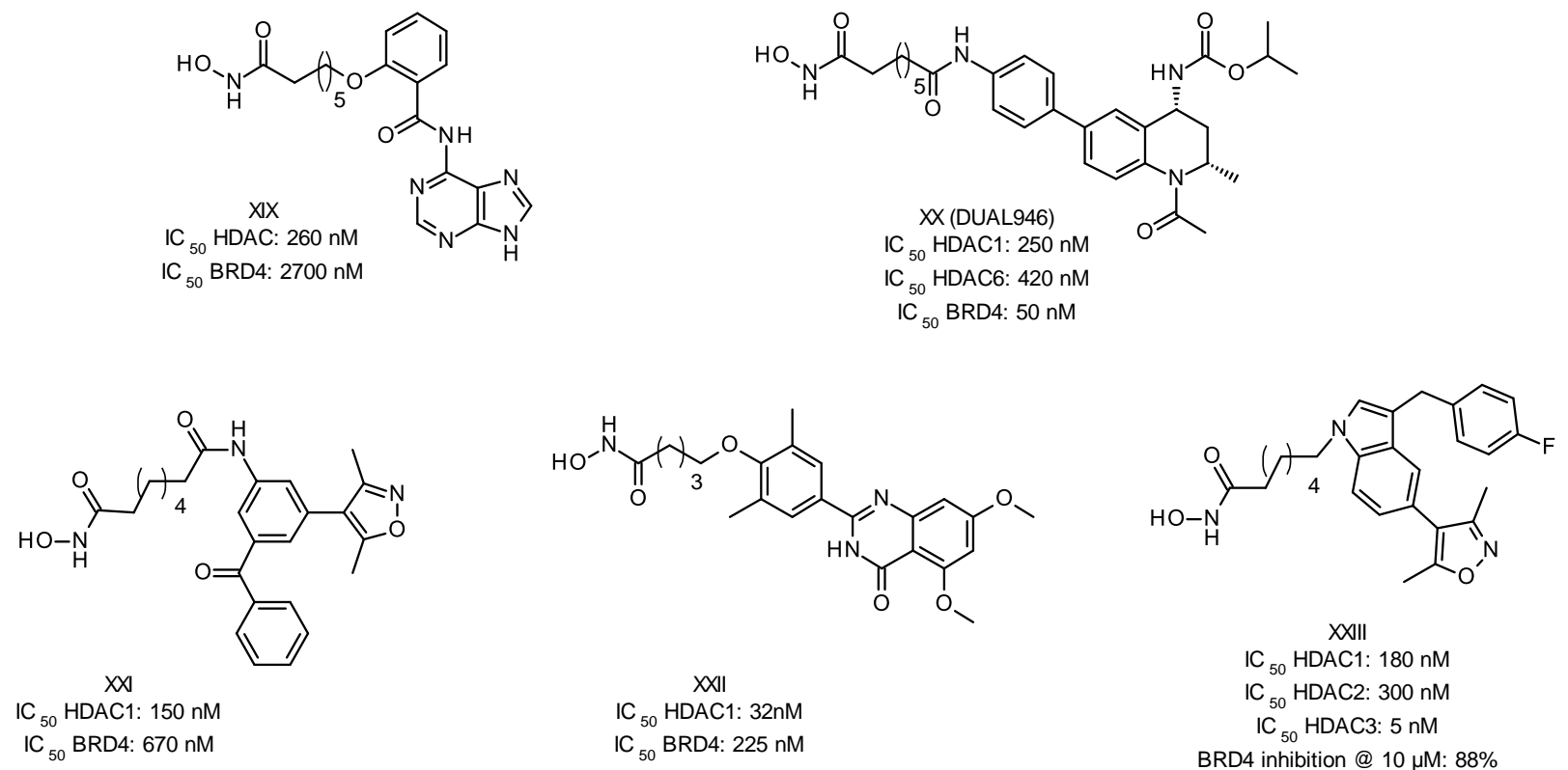

Figure 4: Previously reported dual HDAC/BRD inhibitors

Therefore we wanted to focus on the design of dual targeting inhibitors based on isoform selective HDACi. We have previously reported the structural guided design, optimization and synthesis of benzhydroxamic acids as potent and selective HDAC8 inhibitors [64, 80]. These inhibitors were used as starting point, as we set to modify their structure by including a bromodomain inhibiting scaffold. We decided to target the BRPF1 bromodomain rather than the extensively studied BRD4 from the bromodomain and extra-terminal motif (BET) family. BRPF1 was chosen in the current study due to the reported activity of BRPF1 inhibitors against several cancer cell lines as well as due to the availability of crystal structures in complex with inhibitors. In addition, some BRPF1 inhibitors were reported to selectively inhibit it over other bromodomains and BRPF isoforms. Guided by molecular modelling studies, the essential structural features for binding to both targets were merged to come up with dual targeting inhibitors for HDAC8 and BRPF1. Moreover, we extended the scope of our dual targeting inhibitors to selectively target HDAC6 and BRPF1. We report on the synthesis and in vitro testing of dual targeting inhibitors against specific HDAC isoforms and non-BET bromodomains.

\section{Results and discussion}

\subsection{HDAC8/BRPF1 inhibitors}

Our previously reported HDAC8 inhibitors were designed, so that the benzhydroxamic acid moiety, which occupies the lysine tunnel and chelates the zinc ion, is linked to an aromatic cap group through amine, amide, inverse amide and ether moieties. These two-atom linkers provided additional interactions with the enzyme, and together with the meta-substitution pattern contributed to the HDAC8 selectivity [64]. According to our experience with HDAC8 inhibitors, metasubstitution of the cap group with respect to the benzhydroxamic acid moiety is important for selective inhibition. These findings were also supported by other groups $[61,81]$. In the current work, we first maintained this substitution pattern and chose the 1,3-dimethylquinolin-2-one to 
serve as a cap group and BRPF targeting scaffold. This moiety was selected as it contains the essential features to bind BRPF1, namely the $N$-methyl and carbonyl groups to fit in the acetyllysine binding pocket, and the 3-methyl substituent to increase the hydrophobic interactions with the bromodomain [24]. This ring is also chemically advantageous since it can be easily synthesized and functionalized with an amino group at position 6 to attach the benzhydroxamic acid moiety. Finally, BRDi containing this scaffold showed nanomolar potency against BRPF1, and excellent selectivity over other bromodomains [24, 25]. Compounds 17a,b and 20a,b were generated (Figure 5) by retaining the amine and inverse amide two-atom linkers as found in our original HDAC8i. Meanwhile in compounds 23a,b, we introduced a sulfamoyl linker [61] to retain the bent conformation of the original BRPF1 inhibitor [24]. The previous compounds are designed to block either of the targets. We then designed a structurally different dual HDAC8/BRPF1 inhibitor 32. The idea here was not to modify the cap group of our previously reported selective HDAC8i XVIII but rather to attach it as an intact unit through a relatively longer linker to the 1,3dimethylquinolin-2-one scaffold (Figure 5).
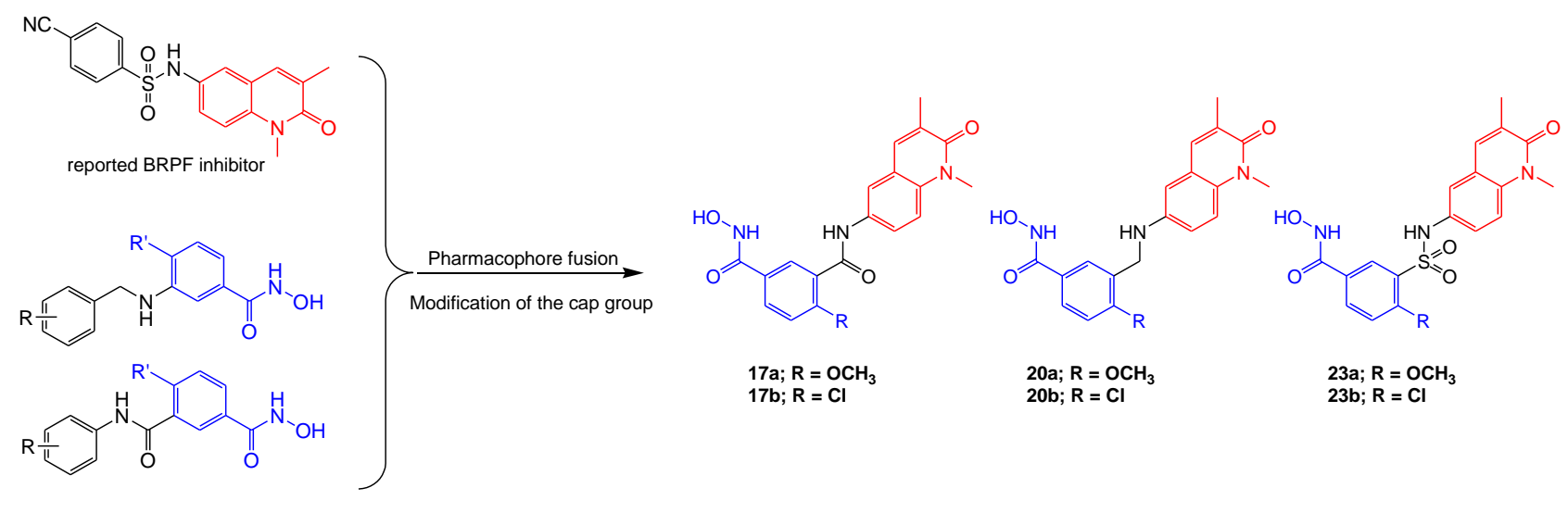

reported HDAC8 inhibitors

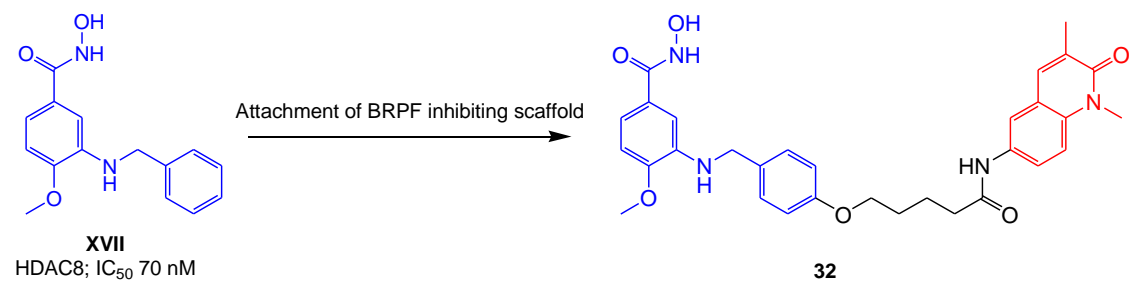

Figure 5: Design of dual targeting HDAC8/BRPF1 inhibitors

We determined the activity of compounds $\mathbf{1 7 a}, \mathbf{b}, \mathbf{2 0 a}, \mathbf{b}$ and $\mathbf{2 3 a}, \mathbf{b}$ on human recombinant HDAC8 (Table 1). As expected, all the compounds showed a good inhibitory activity, with the amide derivatives $\mathbf{1 7 a}$ and $\mathbf{1 7 b}$ showing the lowest $\mathrm{IC}_{50}$ values $(113$ and $65 \mathrm{nM})$. This was in accordance with our previous observation that this orientation of the amide bond is favorable for the interaction with HDAC8 [64]. Compounds 20a,b, bearing an amine linker, showed lower activity, while the sulfonamides 23a,b displayed the lowest inhibitory activity, albeit $\mathrm{IC}_{50}$ values still remained in the submicromolar range. As expected, docking studies of these meta-substituted derivatives in HDAC8 show the capping group, i.e. the 1,3-dimethylquinolin-2-one scaffold, accommodated in the HDAC8-specific side pocket where it undergoes $\pi-\pi$ stacking interactions with Tyr306 (Figure 6). 


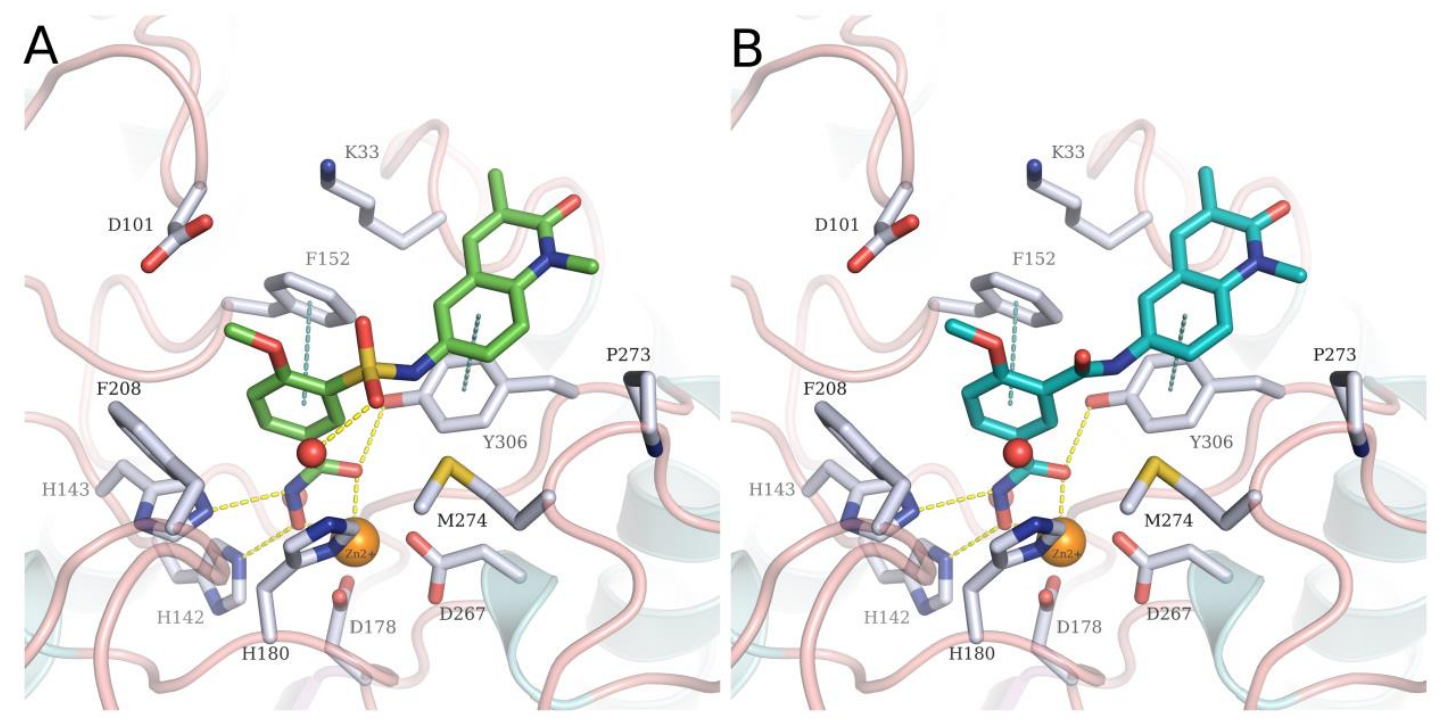

Figure 6: A. Predicted binding mode of 23a (green sticks) in HDAC8 (PDB ID 2V5X). B. Predicted binding mode of 17a (cyan sticks) in HDAC8 (PDB ID 2V5X). The ligands are shown as cyan sticks, side chains of binding site residues as white sticks, water molecules as red spheres and the catalytic zinc ion as orange sphere. Yellow-dashed lines indicate hydrogen bond interactions or metal-coordination, while cyan-dashed lines depict $\pi$ - $\pi$ stacking interactions.

Table 1: Inhibitory activity of the HDAC8/BRPF1 inhibitors against different human HDACs and BRPF1. Recombinant HDAC1,6,8 and fluorogenic peptide substrates (HDAC1,6: ZMAL (Z (Ac)Lys-AMC), HDAC8: Fluor-de-Lys) were used for enzymatic testing. BRPF1 binding was measured by isothermal titration calorimetry.

\begin{tabular}{|c|c|c|c|c|c|}
\hline Compound & $\begin{array}{c}\mathrm{IC}_{50}(\mathrm{nM}) / \% \\
\text { inhibition } \\
\text { HDAC1 }\end{array}$ & $\begin{array}{c}\mathrm{IC}_{50}(\mathrm{nM}) / \% \\
\text { inhibition } \\
\text { HDAC6 }\end{array}$ & $\begin{array}{c}\mathrm{IC}_{50}(\mathrm{nM}) \\
\text { HDAC8 }\end{array}$ & $\begin{array}{c}\mathrm{K}_{\mathrm{d}} \text { BRPF1 } \\
(\mathrm{nM})\end{array}$ & $\begin{array}{c}P 99_{K_{d}} \\
(\mathrm{nM})\end{array}$ \\
\hline $17 \mathbf{a}$ & $6900 \pm 500$ & $709 \pm 174$ & $65 \pm 7$ & 857 & $690-1065$ \\
\hline $17 b$ & n.d. & n.d. & $113 \pm 9$ & n.d. & n.d. \\
\hline $20 \mathrm{a}$ & $\begin{array}{c}0 @ 1 \mu \mathrm{M} \\
31 @ 10 \mu \mathrm{M}^{*}\end{array}$ & $\begin{array}{c}40 @ 1 \mu \mathrm{M} \\
68 @ 10 \mu \mathrm{M}^{*}\end{array}$ & $555 \pm 169$ & n.d. & n.d. \\
\hline $20 \mathrm{~b}$ & $\begin{array}{c}0 @ 1 \mu \mathrm{M} \\
20 @ 10 \mu \mathrm{M}^{*}\end{array}$ & $\begin{array}{c}28 @ 1 \mu \mathrm{M} \\
84 @ 10 \mu \mathrm{M}^{*}\end{array}$ & $3193 \pm 660$ & n.d. & n.d. \\
\hline 23a & $\begin{array}{c}6 @ 1 \mu \mathrm{M} \\
38 @ 10 \\
\mu \mathrm{M}^{* *}\end{array}$ & $\begin{array}{c}21 @ 1 \mu \mathrm{M} \\
64 @ 10 \\
\mu \mathrm{M}^{* *}\end{array}$ & $443 \pm 23$ & 67 & $55-82$ \\
\hline $23 b$ & $\begin{array}{c}13 @ 1 \mu \mathrm{M} \\
31 @ 10 \mu \mathrm{M}\end{array}$ & $\begin{array}{l}13 @ 1 \mu \mathrm{M} \\
59 @ 10 \mu \mathrm{M}\end{array}$ & $560 \pm 42$ & 234 & $198-275$ \\
\hline 32 & $5200 \pm 1100$ & $\begin{array}{c}50 @ 1 \mu \mathrm{M} \\
68 @ 10 \\
\mu \mathrm{M}^{* *}\end{array}$ & $956 \pm 74$ & 4080 & $2544-6022$ \\
\hline
\end{tabular}

n.d.: not determined. For $\mathrm{K}_{\mathrm{d}}$ BRPF1 the P99 interval is given.

* Self-fluorescence of the compounds hindered measurements at concentrations above $10 \mu \mathrm{M}$.

** Solubility problems at higher concentration hindered $\mathrm{IC}_{50}$ value determination.

The most active compound on hHDAC8 17a and the sulfonamide derivatives 23a,b were then selected for the BRPF1 binding assay, where the amide derivative 17a showed only a modest affinity. Interestingly, the sulfonamides 23a,b had a much better affinity with $\mathrm{K}_{\mathrm{d}}$ values in the 
nanomolar range. In order to rationalize the difference in the activities between the sulfonamide and amide derivatives (23a and 17a, respectively), docking studies were performed into the crystal structure of BRPF1 in complex with NI-57 (PDB ID 5MYG) using Glide (Schrödinger LLC, NEW York, USA). Our docking studies revealed that compounds bearing a sulfonamide linker, as exemplified by 23a in (Figure 7A), could adopt a highly similar binding conformation as the cocrystallized ligand. The quinolinone ring of 23a is embedded in the acetyllysine site, showing the conserved hydrogen bond interaction with Asn708 and a water molecule mediated hydrogen bond with Tyr665. In addition, two $\pi-\pi$ stacking interactions between the side chain of Phe714 and the quinolone ring on the one hand and the phenyl ring on the other hand, were observed. Meanwhile, the amide linker in 17a prevents the compound from adopting the bent conformation observed in compounds bearing a sulfonamide linker. The predicted binding mode shows that the benzhydroxamic acid moiety is solvent-exposed (Figure 7B) which explains its significantly decreased activity.

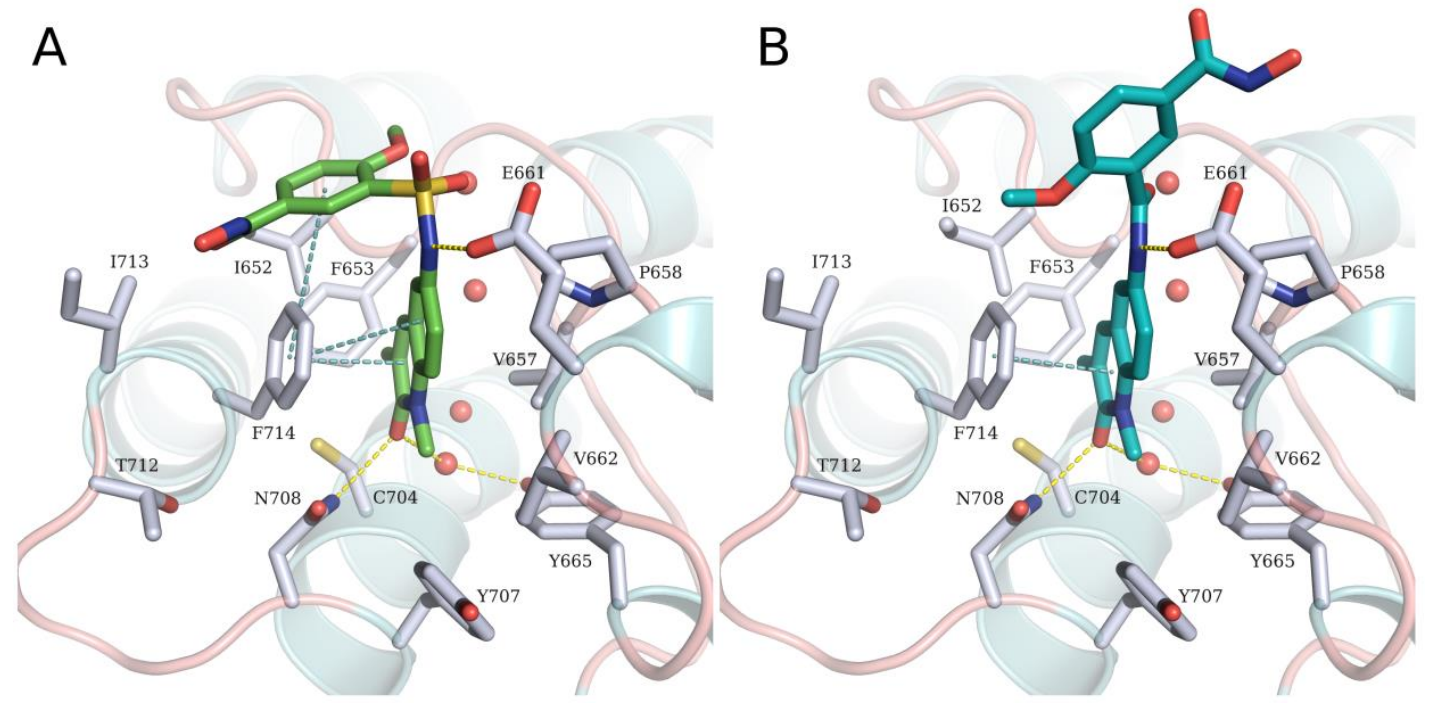

Figure 7: A. Predicted binding mode of 23a (green sticks) in BRPF1. B. Predicted binding mode of 17a (cyan sticks) in BRPF1. The ligands are shown as green sticks, side chains of binding site residues as white sticks, and water molecules as red spheres. Yellow-dashed lines indicate hydrogen bond interactions and cyan-dashed lines $\pi-\pi$ stacking interactions.

We then tested the activity of the most promising compounds on the class I member HDAC1 and class IIb HDAC6, where they generally showed weak inhibition (Table 1). From this series, we were able to identify compounds 23a,b as nanomolar inhibitors of both HDAC8 and BRPF1, which showed low in vitro activity against HDAC1 and 6.

Compound 32 showed only a modest activity against hHDAC8 and only weak micromolar activity against BRPF1.

\subsection{HDAC6/BRPF1 inhibitors}

In order to target HDAC6, we took advantage of the common structure characteristics of selective HDAC6 inhibitors [81]. They are usually aromatic hydroxamic acids with a cap group located in the para position. The linker consists of one to three atoms often including a methylene group. As we already have the bulky 1,3-dimethylquinolin-2-one as a cap group, we hypothesized that shifting it to the para-position would shift the activity to HDAC6, and hence dual HDAC6/BRPF1 inhibitors could be obtained (Figure 8). For this series, we generally retained the sulfamoyl linker since the 
compounds containing this linker 23a,b from the HDAC8/BRPF1 series showed the highest affinity for BRPF1 bromodomain. While in compound $\mathbf{3 7}$ we retained the two-atom sulfamoyl bridge, we incorporated an additional methylene group in compounds $\mathbf{4 4 a , b}$. To further prove the effect of the substitution pattern on HDAC isoform selectivity, compounds with meta substitution pattern 51a,b were synthesized as negative controls for HDAC6 inhibition (isomers of 44a,b respectively).

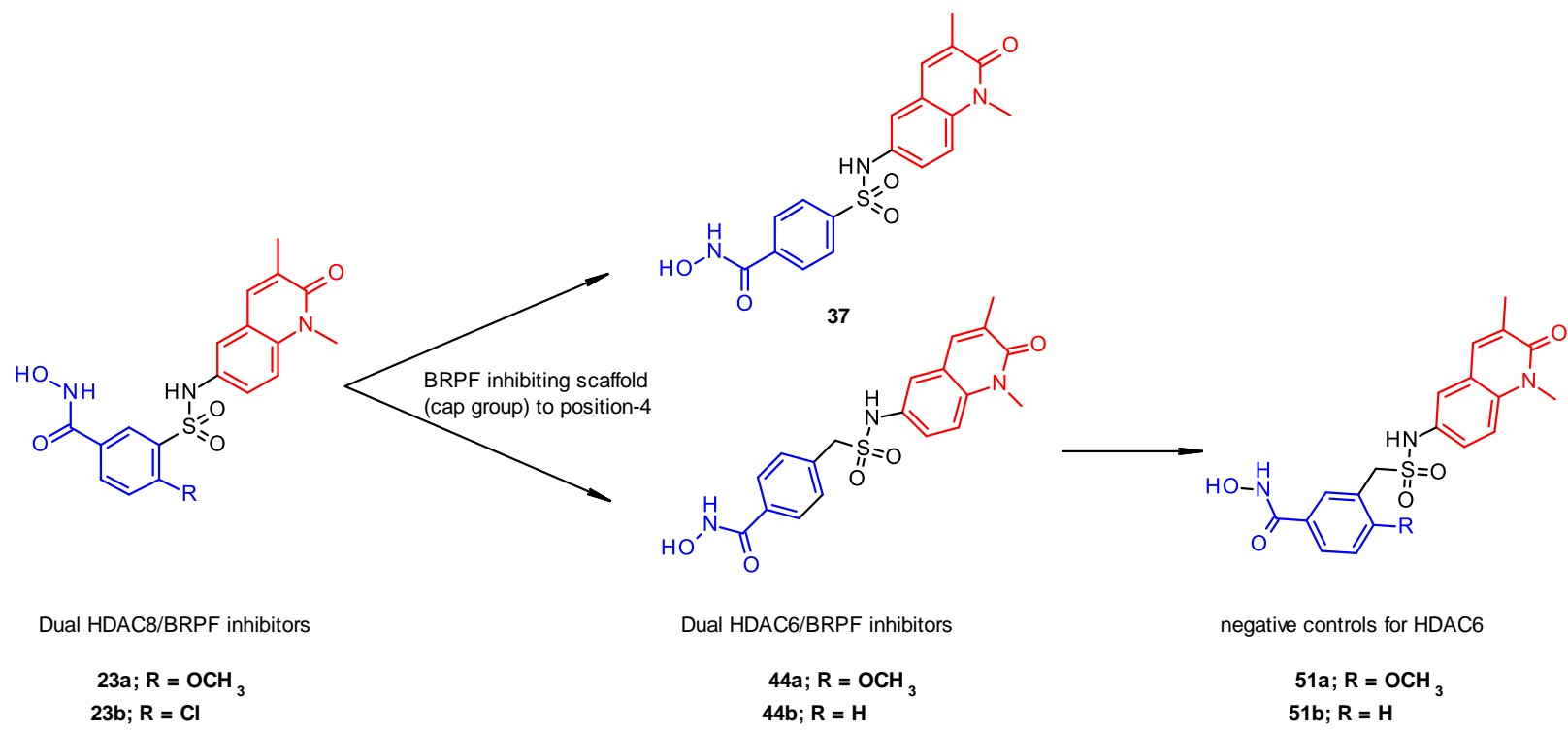

Figure 8: Design of dual HDAC6/BRPF1 inhibitors

These five compounds were first tested in vitro for HDAC inhibition, where the para substituted compounds 37 and $\mathbf{4 4 b}$ showed, as expected, $\mathrm{IC}_{50}$ values in the nanomolar range (Table 2). However, both compounds did not show pronounced selectivity and inhibited HDAC1, 6 and 8 in submicromolar concentrations. The observed HDAC6 inhibitory activity could be strongly attributed to the 4-substitution pattern of the cap group, as the meta substituted compounds from the first series 23a,b and the control compound 51b showed only a very weak HDAC6 inhibitory activity. Interestingly, compound 44a did not show the expected HDAC6 activity, despite the 4substitution pattern of the cap group, suggesting that the introduction of an ortho methoxy group (with respect to the cap group) has a negative effect on the activity against HDAC6. Docking of $\mathbf{3 7}$ and 44b into HDAC6 showed that both compounds adopt a highly similar binding mode (Figure 9), where the hydroxamic acid group is able to chelate the catalytic zinc ion in a monodentate fashion and undergo a hydrogen bond interaction with the side chain of Tyr 782 in addition to a water mediated interaction. Meanwhile the quinolone capping group is embedded in a hydrophobic region lined with Phe620 and His500 and undergoes and additional hydrogen bond interaction with Asn494. An additional ortho methoxy substitution, as found in $\mathbf{4 4 a}$, would lead in this case to a steric clash with the side chain of Leu749, which might explain the loss of HDAC6 inhibitory activity. 

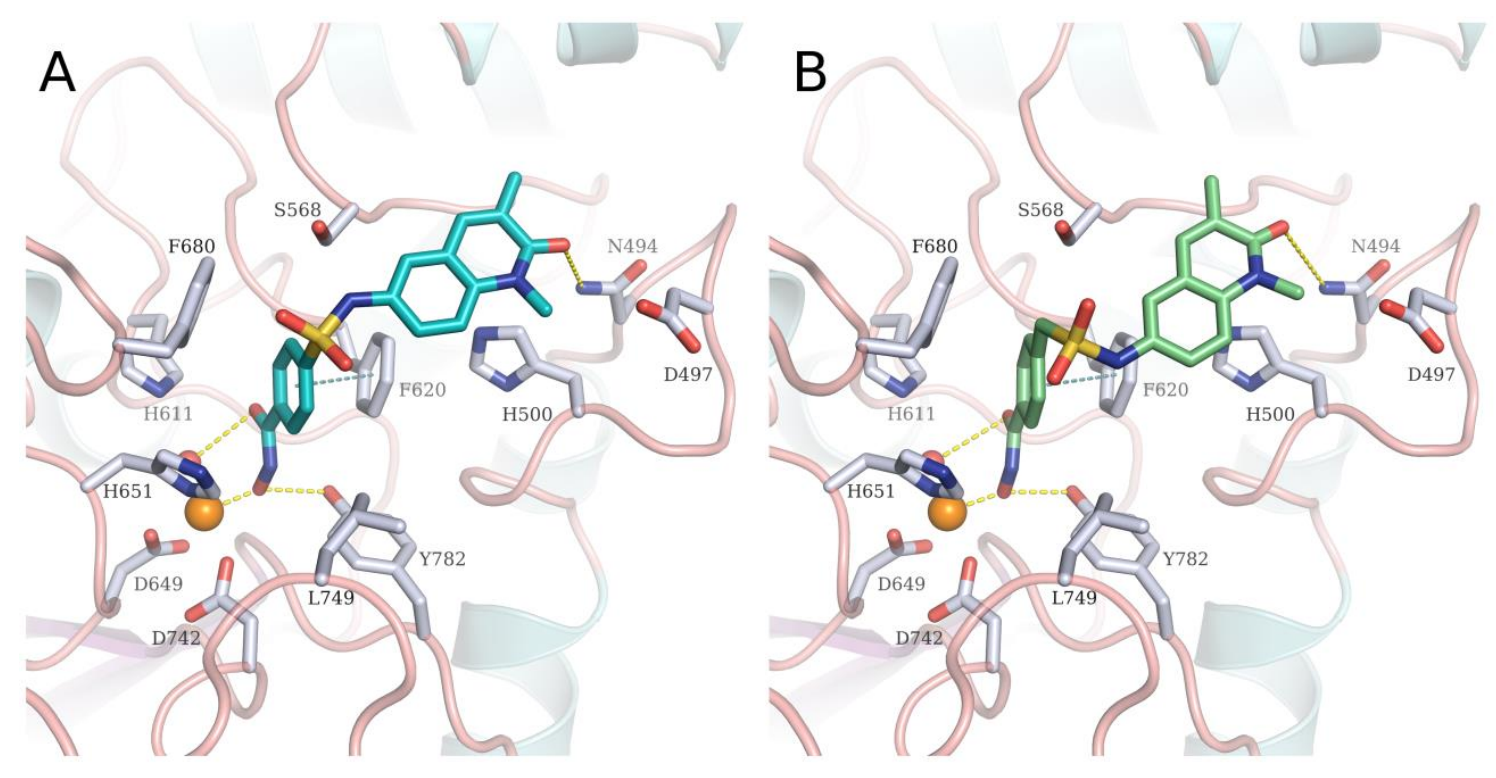

Figure 9: A. Predicted binding mode of 37 (cyan sticks) in HDAC6 (PDB ID 5EDU). B. Predicted binding mode of $\mathbf{4 4 b}$ (green sticks) in HDAC6. The ligands are shown as green sticks, side chains of binding site residues as white sticks, and water molecules as red spheres. Yellow-dashed lines indicate hydrogen bond interactions or metal coordination and cyan-dashed lines $\pi$ - $\pi$ stacking interactions.

Table 2: Inhibitory activity of the HDAC6/BRPF1 inhibitors against different human HDACs and BRPF1. Recombinant HDAC1,6,8 and fluorogenic peptide substrates (HDAC1,6: ZMAL (Z (Ac)Lys-AMC), HDAC8: Fluor-de-Lys) were used for enzymatic testing. BRPF1 binding was measured by isothermal titration calorimetry.

\begin{tabular}{|c|c|c|c|c|c|}
\hline Compound & $\begin{array}{c}\mathrm{IC}_{50}(\mathrm{nM}) / \\
\% \text { inhibition } \\
\text { HDAC1 }\end{array}$ & $\begin{array}{c}\mathrm{IC}_{50}(\mathrm{nM}) / \\
\% \text { inhibition } \\
\text { HDAC6 }\end{array}$ & $\begin{array}{c}\mathrm{IC}_{50}(\mathrm{nM}) \\
\text { HDAC8 }\end{array}$ & $\begin{array}{c}\mathrm{K}_{\mathrm{d}} \mathrm{BRPF} 1 \\
(\mathrm{nM})\end{array}$ & $\begin{array}{c}P 99_{K_{d}} \\
(\mathrm{nM})\end{array}$ \\
\hline $\mathbf{3 7}$ & $797 \pm 282 \mathrm{nM}$ & $344 \pm 41$ & $908 \pm 274$ & 175.2 & $160-193$ \\
\hline $\mathbf{4 4 a}$ & $\begin{array}{c}11 @ 1 \mu \mathrm{M} \\
29 @ 10 \mu \mathrm{M}\end{array}$ & $\begin{array}{c}15 @ 1 \mu \mathrm{M} \\
4610 \mu \mathrm{M}^{*}\end{array}$ & $231 \pm 24$ & 1582 & $1402-1609$ \\
\hline $\mathbf{4 4 b}$ & $545 \pm 59 \mathrm{nM}$ & $152 \pm 13$ & $360 \pm 44$ & 1497 & $1358-1652$ \\
\hline $\mathbf{5 1 a}$ & $\begin{array}{c}4 @ 1 \mu \mathrm{M} \\
29 @ 10 \mu \mathrm{M}\end{array}$ & $\begin{array}{c}1401 \mu \mathrm{M} \\
6310 \mu \mathrm{M}\end{array}$ & $158 \pm 21$ & n.d. & n.d. \\
\hline $\mathbf{5 1 b}$ & $\begin{array}{c}2 @ 1 \mu \mathrm{M} \\
26 @ 10 \mu \mathrm{M}\end{array}$ & $\begin{array}{r}33 @ 10 \mu \mathrm{M} \\
\hline\end{array}$ & $465 \pm 72$ & n.d. & n.d. \\
\hline
\end{tabular}

n.d.: not determined. For $\mathrm{K}_{\mathrm{d}}$ BRPF1 the $P 99$ interval is given.

* Solubility problems at higher concentration hindered $\mathrm{IC}_{50}$ value determination.

The para-substituted compounds 37 and 44a,b were also tested in the BRPF1 binding assay (Table 2), where only 37 showed a nanomolar $K_{d}$ value. The introduction of the additional methylene group in the linker of $\mathbf{4 4 a , b}$ remarkably decreased the BRPF1 affinity (almost 9 fold decrease for 44b compared to 37). In order to comprehend the observed negative effect of an additional methylene group in the linker on the BRPF1 affinity, we first performed docking into the crystal structure of BRPF1 as previously described. Compound 37 could maintain the same binding conformation as the co-crystallized ligand, where the quinolinone ring shows the conserved hydrogen bond interaction with Asn708 and a water mediated hydrogen bond with Tyr665, in addition to $\pi-\pi$ stacking interactions between the side chain of Phe714 (Figure 10A). Moreover, the 
benzhydroxamic moiety is placed in a perpendicular T-shaped orientation to the side chain of Phe 714 where it can undergo $\pi-\pi$ stacking interactions. Meanwhile, the docking pose of compound 44b shows that it similarly adopts a bent conformation, where the benzhydroxamic moiety is still placed in the vicinity of Phe714 (Figure 10B). Notably, the predicted binding mode compound 37 perfectly overlaps with the cocrystallized analogue NI-57, while in 44b the benzhydroxamic group shows a strong deviation (Figure 10C). We postulated that, owing to the flexibility of the methylene-sulfamoyl linker in $\mathbf{4 4 b}$, the predicted binding mode is not stable. In order to investigate this hypothesis, molecular dynamics (MD) simulations of the predicted complexes of BRPF1 with 37 and 44b were performed using Amber16. These revealed that, as expected, the predicted binding mode of $\mathbf{3 7}$ in BRPF1 is highly stable with the ligand having a root mean square deviation (RMSD) below $2.5 \AA$ throughout the $100 \mathrm{~ns}$ MD simulation (Figure 10D and Video 1 suppl.). Meanwhile, the binding mode of $\mathbf{4 4 b}$ is highly unstable (Figure 10E) and the benzhydroxamic moiety becomes majorly solvent-exposed (Video 2 suppl.). The applied MD simulation setup was also validated using the cocrystal structure of BRPF1 with NI-57 (Figure S7, Supporting Information).

A

B
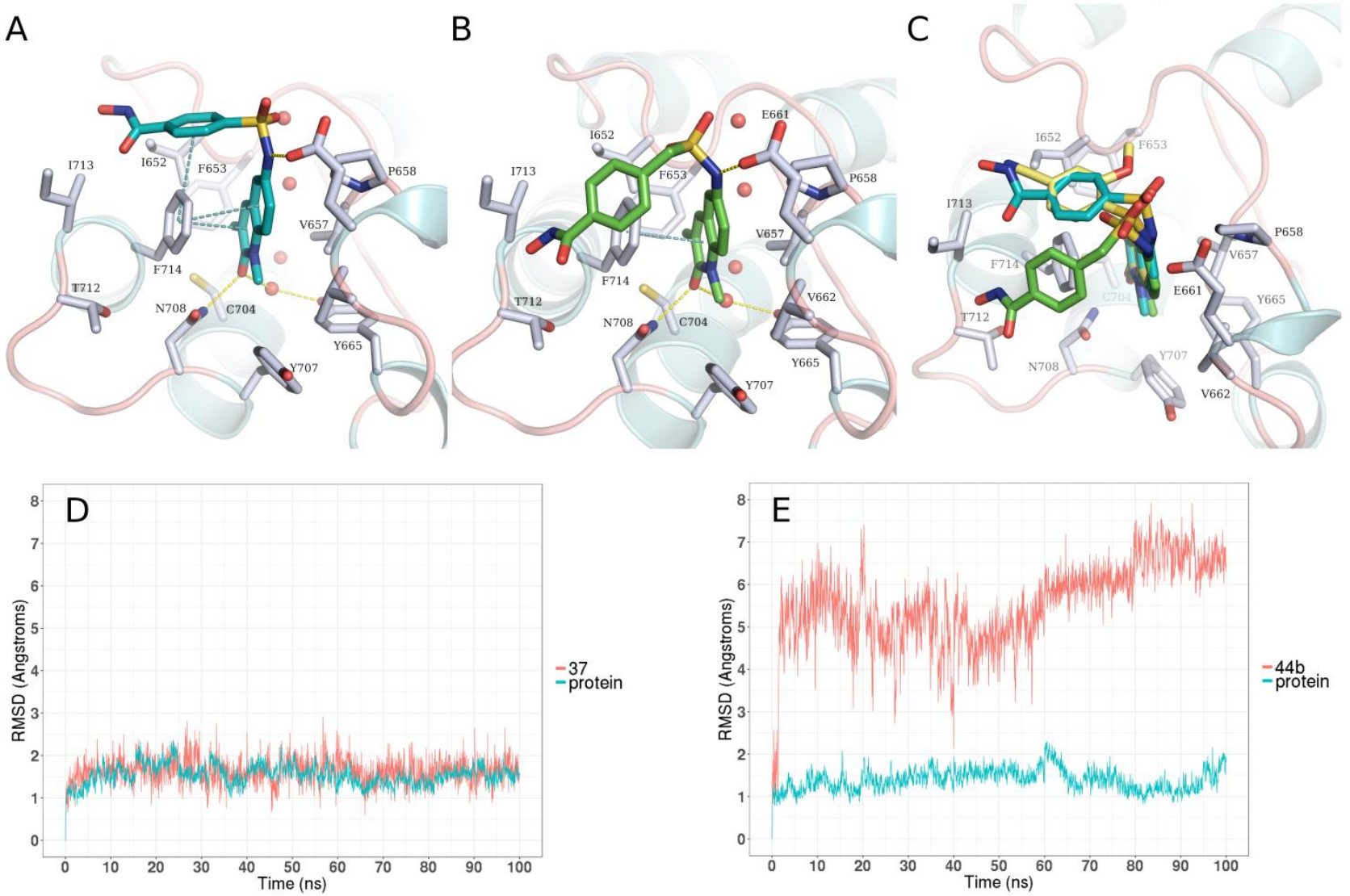

Figure 10: A. Predicted binding mode of 37 (cyan stick) in BRPF1. B. Predicted binding mode of 44b (green sticks) in BRPF1. C. Overlay of the predicted binding mode of 37 (cyan stick) and 44b (green sticks) with the cocrystallized ligand NI-57 (yellow sticks). Side chains of binding site residues are depicted as white sticks, and water molecules as red spheres. Yellow-dashed lines indicate hydrogen bond interactions and cyan-dashed lines $\pi-\pi$ stacking interactions. D. RMSD plot of the MD simulation of $\mathbf{3 7}$ in BRPF1. E. RMSD plot of the MD simulation of $\mathbf{4 4 b}$ in BRPF1. 
We then tested the activity of the most promising compounds on HDAC1 where they generally showed no or low inhibition (Table 2). Testing on HDAC8 showed that compound 44a has a good inhibitory activity against $\mathrm{HDAC} 8$ with an $\mathrm{IC}_{50}$ value in the low nanomolar range.

Among this group of inhibitors, compound $\mathbf{3 7}$ appeared to be the best HDAC6/BRPF1 dual inhibitor showing a nanomolar in vitro inhibitory activity against both targets, and in vitro selectivity over HDAC1 and 8.

In addition we synthesized several control compounds including a dimeric BRPF1i compound 38 (Scheme 3) and carboxylic esters 21, 35 and 42b (analogs of 23a, 37 and 44b) lacking the hydroxamic acid functionality.

\subsection{Cellular assay}

The first objective of our cellular assays was to determine the potential toxicity of our compounds on normal cells. Therefore, the compounds were tested in a human epithelial kidney cell line (HEK293). We also incorporated some of the intermediate carboxylic acids and esters in the assay as negative controls. The majority of the compounds showed no effect on HEK 293 cells, except for 32 which displayed only $15 \%$ viability of the cells. It is also worth mentioning that some esters showed more toxic effects compared to their corresponding hydroxamic acids, such as $\mathbf{2 1}$ and $23 \mathbf{a}$. Viability of HEK293 cells upon treatment with our compounds is provided in supporting information, S5.

Our second objective was to assess the potential antiproliferative effects on cancer cell lines. As previously mentioned, HDAC and BRD are interesting targets for the anticancer therapy, and their inhibitors showed cytotoxic activity against different tumors. Our main focus was acute myeloid leukemia (AML) cell lines (THP-1 and HL60) based on some previous reports showing evidence of significance of HDAC6 [82] and HDAC8 [83, 84] as well as BRPF [15-17] inhibition in these cells. We tested our most promising compounds 23a,b (HDAC8/BRPF1), 37 and 44b (HDAC6/BRPF1) together with their esters as negative controls- on THP-1 and HL60 cell lines to investigate if the compounds in vitro inhibitory activity could be translated into cellular anticancer activity (Table 3).

Although all the hydroxamic acids showed no or weak growth inhibition on the cells, a much stronger inhibition was generally observed for the esters, and the $\mathrm{GI}_{50}$ value of $\mathbf{2 1}$ was determined to be around $5.5 \mu \mathrm{M}$. The activity of the esters could be attributed to the BRPF1 inhibiting scaffold. In fact, both 21 and the potent BRPF1 inhibitor 13-d [24] have almost the same $\mathrm{GI}_{50}$ value on THP1 cells. The corresponding hydroxamic acids, however, did not show an inhibition, despite their bromodomain inhibitory scaffold. We assumed that since the esters are more lipophilic than the hydroxamic acids ( $\log \mathrm{P}$ value for $\mathbf{2 1}$ is 1.83 compared to 1.09 for 23a, calculated with ChemDraw Ultra 8), they should have better cell permeability, and consequently better cellular activity than the hydroxamic acids.

To get insight into the cellular activity of our hydroxamic acids, western blotting experiments were performed with our best HDAC6 inhibitor 44b ( $\mathrm{IC}_{50}$ value: $152 \mathrm{nM}$, Table 2) in the two cell lines THP-1 and HL60. The cells were incubated with 44b or SAHA (reference compound), and then cell lysates were blotted against acetylated- $\alpha$-tubulin (HDAC6 substrate), acetylated-histone H3 (HDAC1 substrate), and glyceraldehyde 3-phosphate dehydrogenase (GAPDH) as a loading control (Figure 11). At lower concentrations, 44b showed negligible or no induction of tubulin acetylation in both cell lines, whereas some degree of acetylation was observed at $10 \mu \mathrm{M}$. The lack of hyperacetylation at lower concentrations is in line with the antiproliferative assays, where the 
compound showed inhibition only at a high concentration of $100 \mu \mathrm{M}$. The western blots were quantified by determining the ratio of acetylated tubulin or acetylated histone 3 versus GAPDH (Table 4). These results further supported our postulation that our hydroxamic acids have poor permeability and therefore did not show remarkable cellular activity. It is worth mentioning that the dimeric compound 38 (Scheme 3 and later discussed in 2.5.2.) showed a promising growth inhibition on THP-1 cells at $1 \mu \mathrm{M}$. However, its relatively poor solubility hindered further testing at higher concentrations and consequently $\mathrm{GI}_{50}$ determination.

Based on these findings, we then aimed to modify some of our hydroxamic acids in order to acquire better cellular permeability. To achieve that, we masked the hydroxamic acid functionality in 23a and $\mathbf{4 4 b}$ by synthesizing the corresponding benzyl and para-acetoxy-benzyl ester prodrugs of hydroxamic acids 59a,b and 60b (Figure 12) as prodrugs. Masking hydroxamic acids was recently reported as an approach to overcome problems like fast elimination, decreased cellular uptake and poor tissue penetration caused by the highly polar hydroxamic acid group [85-90]. In addition, paraacetoxybenzyl-based prodrugs were shown to be completely converted to the parent hydroxamic acid in plasma [91]. Unfortunately, even these masked hydroxamic acids 59a,b and 60b $(\log \mathrm{P}$ values ranging from 2.51-3.08, calculated with ChemDraw Ultra 8) did not show an improvement in the activity against either THP-1 or HL60 cell lines. Compounds 60a,b showed only promising inhibition at $100 \mu \mathrm{M}$, but not at lower concentrations. 
Table 3: Antiproliferative activity on acute myeloid leukemia cells THP-1 and HL60. Growth inhibition was determined using the CellTiter 96AQueous Non-Radioactive Cell Proliferation Assay.

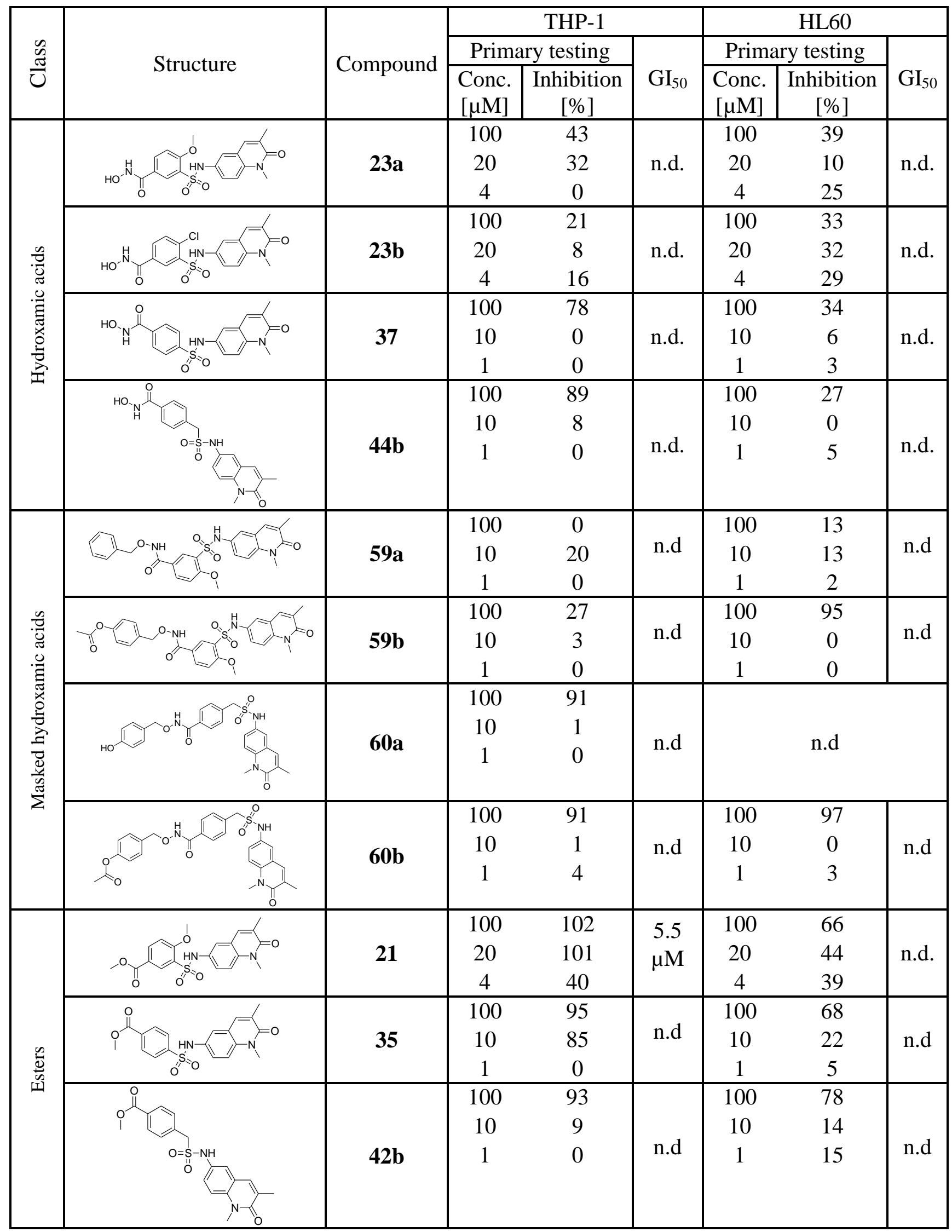




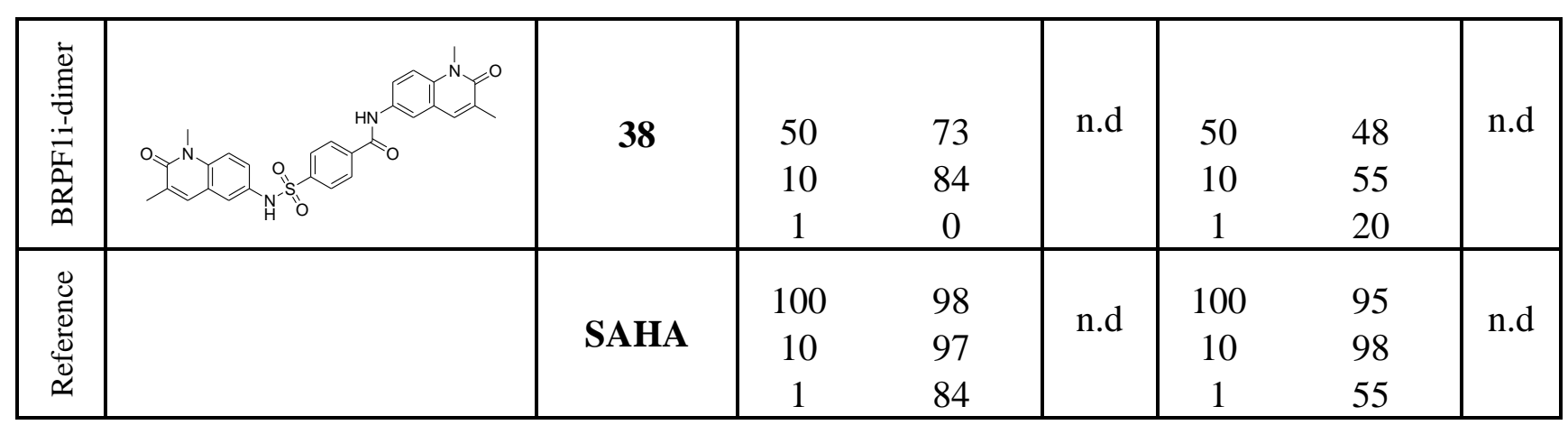

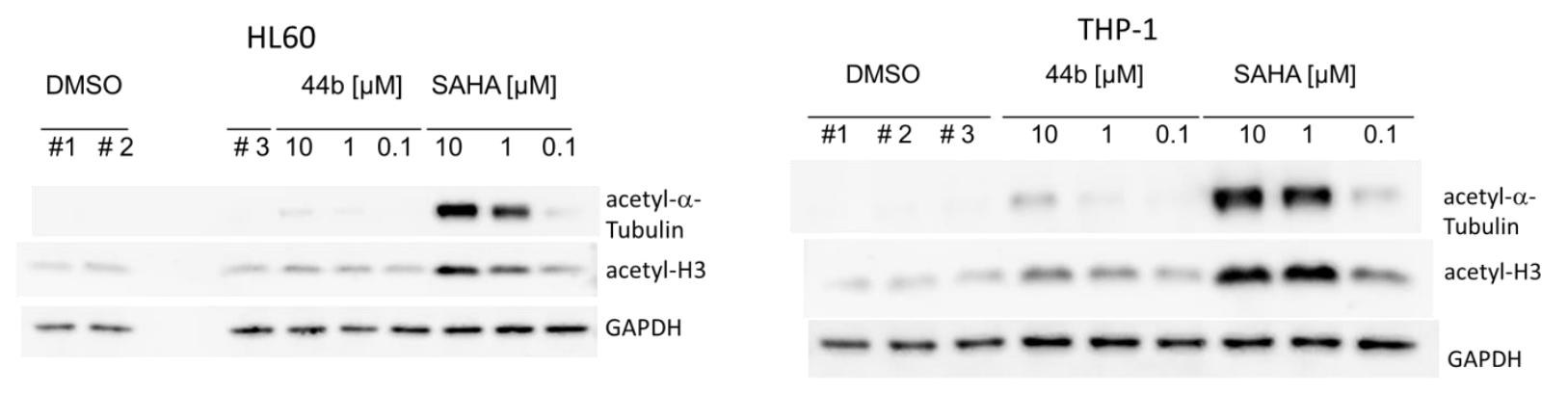

Figure 11: Western blots of acetyl- $\alpha$-tubulin, acetyl-H3, and GAPDH after treatment of HL60 and THP-1 cells with SAHA and 44b. GAPDH and DMSO were used as loading and negative controls.

Table 4: Quantification of Western Blots in THP-1 and HL60 Cells

\begin{tabular}{|c|c|c|c|c|}
\hline \multirow{2}{*}{ Compound } & \multicolumn{2}{|c|}{ THP-1 } & \multicolumn{2}{c|}{ HL60 } \\
\cline { 2 - 5 } & $\begin{array}{c}\text { Ac- } \\
\text { tubulin/GAPD } \\
\mathrm{H}\end{array}$ & $\begin{array}{c}\text { Ac- } \\
\text { H3/GAPDH }\end{array}$ & $\begin{array}{c}\text { Ac- } \\
\text { tubulin/GAPD } \\
\mathrm{H}\end{array}$ & $\begin{array}{c}\text { Ac- } \\
\text { H3/GAPDH }\end{array}$ \\
\hline DMSO & 1.00 & 1.00 & 1.00 & 1.00 \\
\hline 44b $10 \mu \mathrm{M}$ & 7.67 & 2.63 & 7.36 & 1.38 \\
44b $1 \mu \mathrm{M}$ & 2.51 & 1.98 & 4.96 & 1.66 \\
44b $0.1 \mu \mathrm{M}$ & 2.64 & 1.53 & 1.36 & 0.90 \\
\hline SAHA $10 \mu \mathrm{M}$ & 78.80 & 8.78 & 309.78 & 5.73 \\
SAHA $1 \mu \mathrm{M}$ & 68.15 & 10.09 & 146.10 & 2.57 \\
SAHA $0.1 \mu \mathrm{M}$ & 6.21 & 2.78 & 8.36 & 1.12 \\
\hline
\end{tabular}




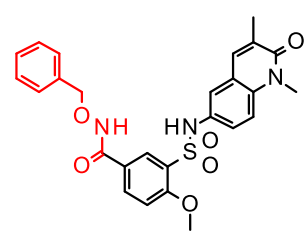

$59 a$

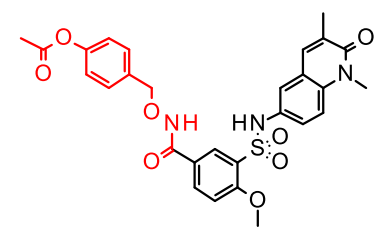

$59 b$

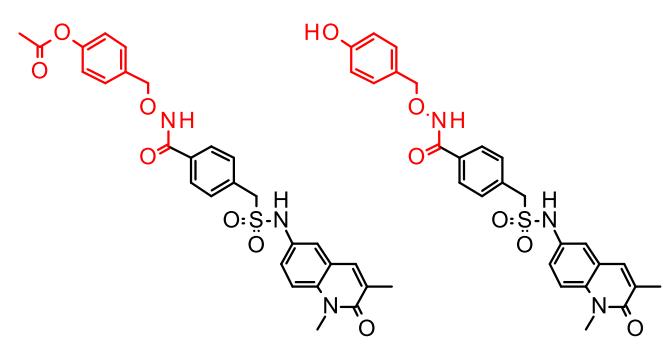

$60 \mathrm{~b}$
$60 a^{*}$

* Phenol intermediate 60a (deacetylated) was obtained as a by-product during the synthesis of $60 \mathrm{~b}$ (acetylated) and was included in the biological testing

Figure 12: Benzyl and para-acetoxy-benzyl ester prodrugs of hydroxamic acids synthesized in the current work.

\subsection{Stability Analysis}

Stability stress tests were carried out to investigate the stability of the synthesized hydroxamic acids, and to see if the masked derivatives are hydrolyzed to release the free hydroxamic acid under assay conditions. We used the hydroxamic acid $\mathbf{4 4 b}$ and the derivative $\mathbf{6 0 b}$ as representatives. For this purpose, the compounds were subjected to standard cellular assay conditions (Dulbecco's Modified Eagle's Medium, DMEM) and also to buffer (in vitro assay) conditions (PhosphateBuffered Saline, PBS pH 7.4). After incubation at $37{ }^{\circ} \mathrm{C}$ for different time intervals, the original compounds and potential hydrolysis products were detected and quantified via HPLC.

We observed that the free hydroxamic acid 44b showed acceptable stability over 4 days for both in cellular assay and in vitro conditions. The prodrg $\mathbf{6 0 b}$ was relatively stable under buffer conditions (70\%) and showed only a $15 \%$ release of $\mathbf{4 4 b}$ as hydrolysis product after 12 hours. After 96 hours several non-identified degradation products could be detected. However, under cellular assay conditions $60 \mathrm{~b}$ was rapidly hydrolyzed (50\% after 4 hours) showing $\mathbf{4 4 b}$ as the major degradation product. After $24 \mathrm{~h}$, we could only detect 44b without any traces of $\mathbf{6 0 b}$. The data clearly showed that the masked prodrug was indeed hydrolyzed to release the active hydroxamic acid under cellular assay conditions. However, this also suggested that the rapid hydrolysis might be responsible that the required concentration of the masked hydroxamic acid couldn't be delivered to cells, where the hydrolysis is supposed to occur. Experimental details and graphs are provided in the supplementary information (Figure S6, Supporting Information).

\subsection{Chemistry}

\subsubsection{Synthesis of HDAC8/BRPF1 inhibitors}

Synthesis of the 6-amino-1,3-dimethylquinolin-2-( $1 H)$-one (5), the common starting material for the compounds, was achieved using the procedure reported by Igoe et al [24] with some modifications (Scheme S.1.1, supporting information). Briefly, 3-methylquinoline (1) was converted to 3methylquinolin-2(1H)-one (2) in two steps using 3-chloroperbenzoic acid then benzoyl chloride. Methylation with iodomethane afforded the $N$-methyl derivative (3), which was then nitrated to yield 1,3-dimethyl-6-nitroquinolin-2-(1H)-one (4). Our main modification to the procedure was the conversion of the latter compound to the targeted amine $\mathbf{5}$ using a microwave assisted reduction protocol [92]. This enabled a much faster, more efficient, and easier reduction process than the 
reported stannous chloride based procedure. To synthesize the first dual HDAC8/BRBF inhibitors 17a,b, 20a,b and 23a,b, the required starting materials were prepared as reported in the literature (Scheme S.1.1, supporting information) [93-95]. The synthesis of the target compounds is illustrated in Scheme 1. Briefly, compounds 17a,b were prepared starting from the 5methoxycarbonyl-2-substitutedbenzoic acids (9a,b) which were first activated using oxalyl chloride, and then coupled to 6-amino-1,3-dimethylquinolin-2- $(1 H)$-one (5) to give methyl 3-[(1,3dimethyl-2-oxo-1,2-dihydroquinolin-6-yl)carbamoyl]-4-substitutedbenzoates (15a,b). These were finally hydrolyzed to yield the corresponding carboxylic acids 16a,b. For inhibitors 20a,b, sodium triacetoxyborohydride was utilized for the reductive amination of aldehydes $\mathbf{8 a}, \mathbf{b}$ and amine $\mathbf{5}$ to synthesize the esters $\mathbf{1 8 a}, \mathbf{b}$, again followed by hydrolysis to afford the 3-[(1,3-dimethyl-2-oxo-1,2dihydroquinolin-6-ylamino)methyl]-4-substitutedbenzoic acids (19a,b). Carboxylic acid 22b was prepared directly from the aromatic sulfonyl chloride $\mathbf{1 3 b}$ and amine $\mathbf{5}$ using pyridine as a base. The same protocol for the synthesis of intermediate 22a afforded a major byproduct (which was extremely insoluble in common solvents, and unfortunately could not be characterized). This necessitated an alternative route, where compound 5 was reacted with the ester derivative $\mathbf{1 4}$ to first give methyl 3-[(1,3-dimethyl-2-oxo-1,2-dihydroquinolin-6-yl)sulfamoyl]-4-methoxybenzoate (21), which was further hydrolysed to yield the carboxylic acid 22a. The desired hydroxamic acids $\mathbf{1 7} \mathbf{a}, \mathbf{b}, \mathbf{2 0 a}, \mathbf{b}$ and 23a,b were finally obtained from the corresponding carboxylic acids $\mathbf{1 6} \mathbf{a}, \mathbf{b}, \mathbf{1 9 a}, \mathbf{b}$ and 22a,b using PyBOP as an activating agent and $O$-(tetrahydro- $2 \mathrm{H}$-pyran-2-yl)hydroxylamine followed by cleavage of the protecting group [65]. We adopted this method rather than the classical one (reaction with hydroxylamine hydrochloride and a strong base like $\mathrm{KOH}$ ), as this method facilitated the purification of the final hydroxamic acids.
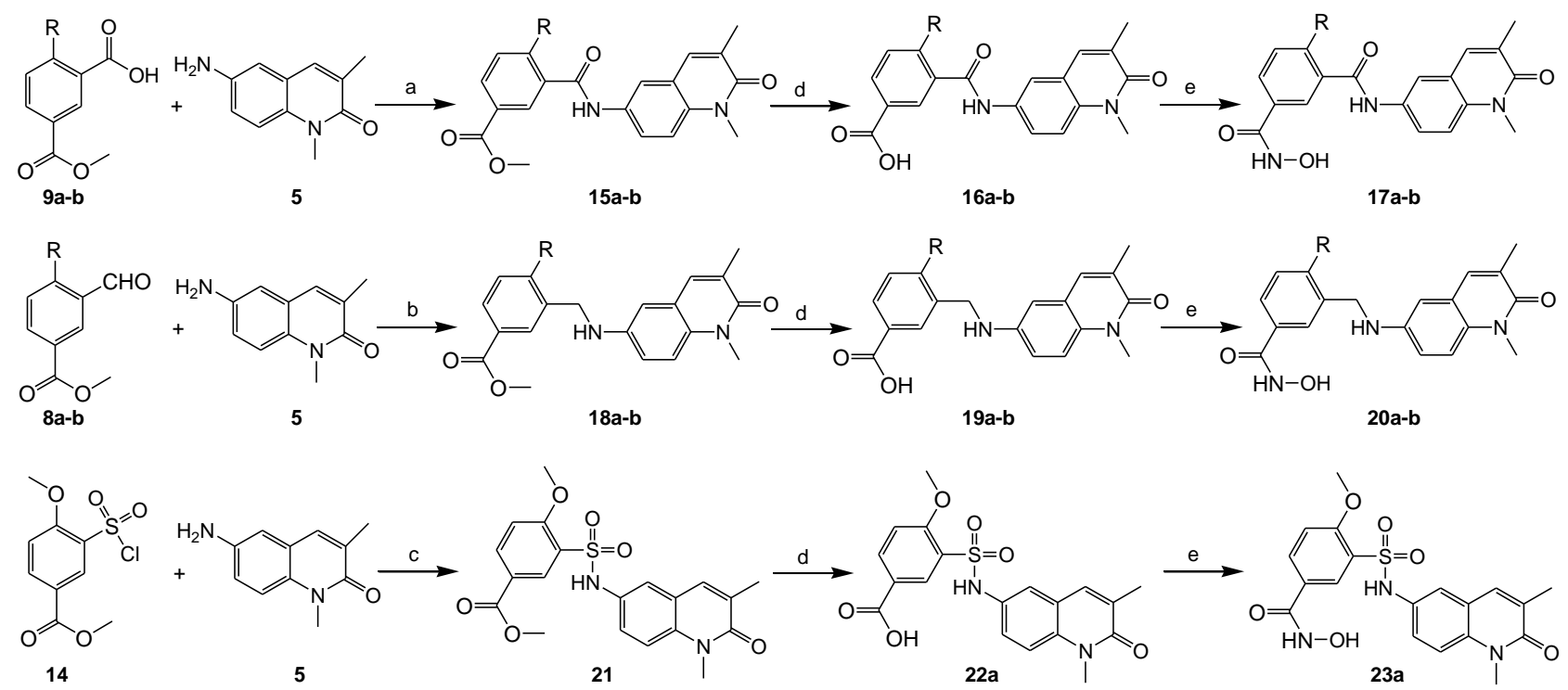

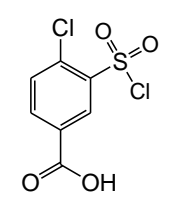

$13 b$

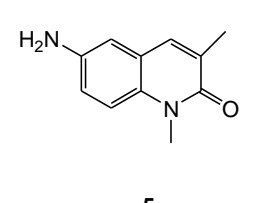

5

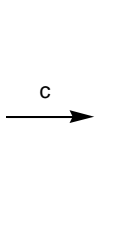

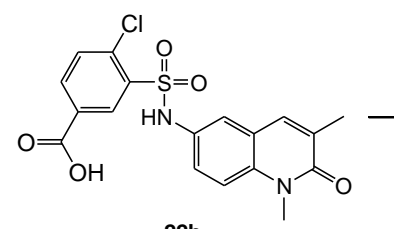

22b

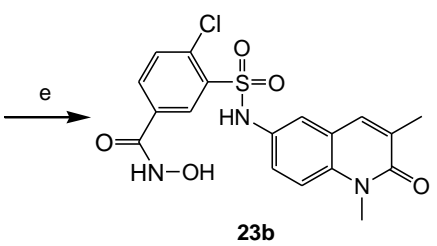

$\mathbf{a} ; \mathbf{R}=\mathrm{OCH}_{3} \quad \mathbf{b} ; \mathbf{R}=\mathrm{Cl}$

Scheme 1: Synthesis of dual HDAC8/BRPF1 inhibitors 17a,b, 20a,b and 23a,b. Reagents and conditions: (a) i) oxalyl chloride, cat. DMF, $\mathrm{CH}_{2} \mathrm{Cl}_{2}$, ii) DIPEA, $\mathrm{CH}_{2} \mathrm{Cl}_{2}$; (b) $\mathrm{Na}(\mathrm{AcO})_{3} \mathrm{BH}$, 
$\mathrm{CH}_{3} \mathrm{COOH}$, THF; (c) pyridine; (d) i) aqu. $\mathrm{NaOH}, \mathrm{MeOH}$, reflux, ii) c. $\mathrm{HCl}$; (e) i) PyBOP, DIPEA, $\mathrm{H}_{2} \mathrm{NOTHP}, \mathrm{THF}$, ii) cat. $\mathrm{HCl}, \mathrm{THF}$.

In the case of synthesis of compound 32, it was quiet challenging to find the optimal synthetic sequence. As shown in Scheme 2, the 4-hydroxybenzaldehyde (26) was first alkylated with 5bromovalerate (25) to give the ester $\mathbf{2 7}$, which was then hydrolyzed to the corresponding acid $\mathbf{2 8}$. Again oxalyl chloride served as an activating agent and the resulting acid chloride was reacted with 5 to give $N$-(1,3-dimethyl-2-oxo-1,2-dihydroquinolin-6-yl)-5-(4-formylphenoxy)pentanamide (29). The previously mentioned conditions of reductive amination were not successful for the reaction of 29 with 3-amino-4-methoxybenzoic acid (30), and required a modification by adding trifluoroacetic acid (TFA) [96] to obtain the carboxylic acid 31, which was finally converted to the target compound 32 using the above mentioned protocol.



Scheme 2: Synthesis of dual HDAC8/BRPF1 inhibitor 32. Reagents and conditions: (a) ptoluenesulfonic acid, $\mathrm{CH}_{3} \mathrm{OH}$; (b) $\mathrm{K}_{2} \mathrm{CO}_{3}$, acetone, reflux; (c) $\mathrm{LiOH}_{2} \mathrm{H}_{2} \mathrm{O}$, THF, $\mathrm{H} 2 \mathrm{O}$; (d) i) oxalyl chloride, cat. DMF, $\mathrm{CH}_{2} \mathrm{Cl}_{2}$, ii) DIPEA, $\mathrm{CH}_{2} \mathrm{Cl}_{2}$; (e) $\mathrm{Na}(\mathrm{AcO})_{3} \mathrm{BH}, \mathrm{CF}_{3} \mathrm{COOH}$, THF; (f) i) PyBOP, DIPEA, $\mathrm{H}_{2} \mathrm{NOTHP}, \mathrm{THF}$, ii) cat. $\mathrm{HCl}$, THF.

\subsubsection{Synthesis of HDAC6/BRPF1 inhibitors}

The starting materials for the dual HDAC6/BRPF1 inhibitors were the appropriate sulfonyl chlorides. Trials to directly synthesize the carboxylic acid $\mathbf{3 6}$ from the commercially available 4(chlorosulfonyl)benzoic acid (33) again afforded a major by-product. This product had a reasonable solubility and was identified as 4-[(1,3-dimethyl-2-oxo-1,2-dihydroquinolin-6-yl)sulfamoyl]- $N$ (1,3-dimethyl-2-oxo-1,2-dihydroquinolin-6-yl)benzamide 38 (Scheme 3). In case of 34, 41a,b and 48a,b we decided to start with the sulfonyl chloride esters. Reaction of the corresponding alkyl bromides 40a,b and 47a,b with sodium sulphite and phosphorus pentachloride yielded the aliphatic sulfonyl chlorides 41a,b and 48a,b (Scheme S.1.2., supporting information). Again reaction of these sulfonyl chlorides with $\mathbf{5}$ in pyridine afforded the esters $\mathbf{3 5}, \mathbf{4 2 a}, \mathbf{b}$ and $\mathbf{4 9 a} \mathbf{a}, \mathbf{b}$, which were 
hydrolysed to the carboxylic acids and finally converted to the desired hydroxamic acids $\mathbf{3 7}, \mathbf{4 4 a , b}$ and 51a,b as previously discussed (Scheme 4).<smiles>O=C(O)c1ccc(S(=O)(=O)Cl)cc1</smiles>

33<smiles>Cc1cc2cc(N)ccc2n(C)c1=O</smiles>

$\stackrel{\text { Pyridine }}{\longrightarrow}$

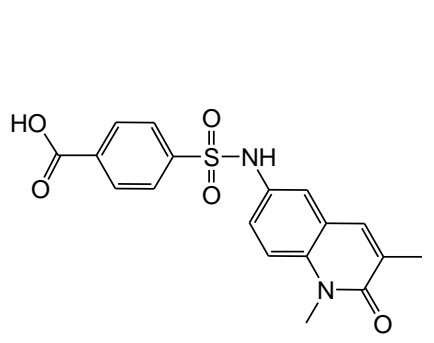

36

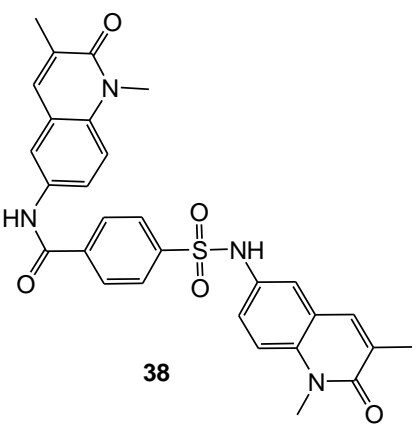

Scheme 3: Synthesis of dimeric BRPF1i 38
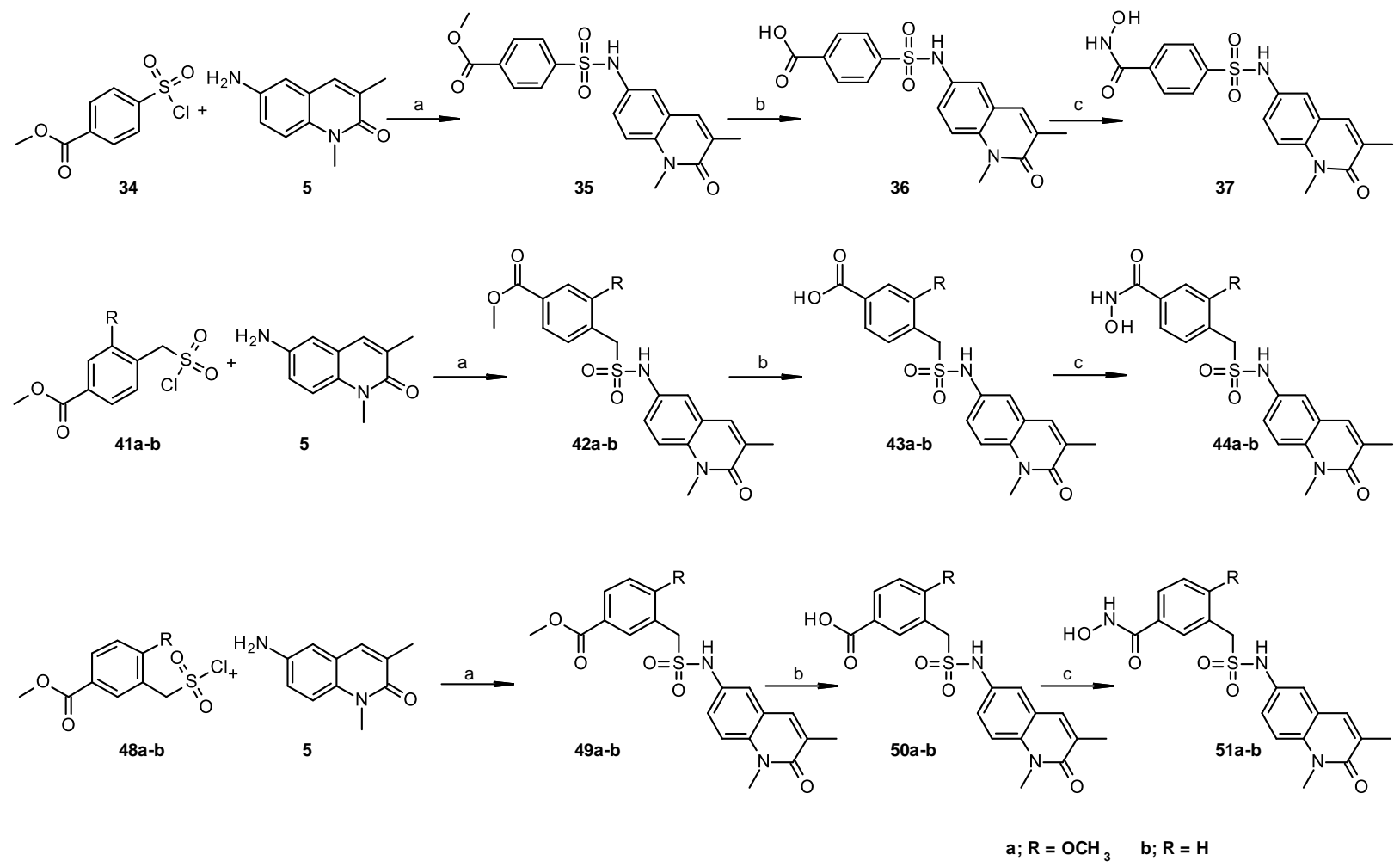

Scheme 4: Synthesis of dual HDAC6/BRPF1 inhibitors 37, 44a,b and 51a,b. Reagents and conditions: (a) pyridne; (b) i) aqu. $\mathrm{NaOH}, \mathrm{CH}_{3} \mathrm{OH}$, reflux, ii) c. $\mathrm{HCl}$; (c) i) PyBOP, DIPEA, $\mathrm{H}_{2} \mathrm{NOTHP}, \mathrm{THF}$, ii) cat. $\mathrm{HCl}$, THF.

\subsubsection{Synthesis of masked hydroxamic acids}

Compounds 59a,b and 60a,b were synthesized as shown in Scheme $\mathbf{5}$ from the corresponding carboxylic acids $\mathbf{2 2 a}$ and $\mathbf{4 3 b}$, respectively. Whereas intermediate 58a was commercially available, intermediate $\mathbf{5 8 b}$ was synthesized following the procedure reported by Rais et al [91] with some modifications (Scheme S.1.3., supporting information). Unlike the protocol for hydroxamic acid synthesis (Schemes 1, 2 and 4), activation of the carboxylic acids using PyBOP to synthesize the masked hydroxamic acid was not optimal and complicated the purification process. Instead, we 
used HATU as an activating agent, since its traces and side products could be efficiently removed by aqueous workup which facilitated purification. It is also worth mentioning that compound 60a was obtained as a deacetylated side product of compound $\mathbf{6 0 b}$ (probably during the hydrazinolysis process due to slightly increased reaction time). It was then purified, characterized, identified and incorporated in our cellular assays.

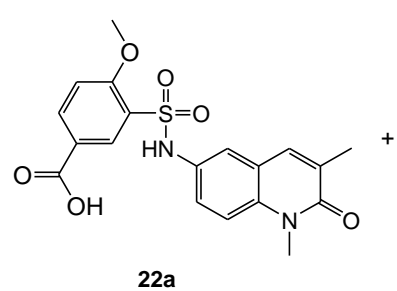

22a
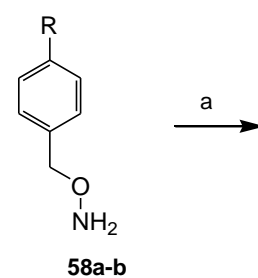

(1)

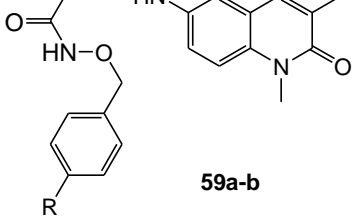<smiles>Cc1cc2cc(NS(=O)(=O)Cc3ccc(C(=O)O)cc3)ccc2n(C)c1=O</smiles>

$43 b$<smiles>CC(=O)Oc1ccc(CON)cc1</smiles>

$58 b$

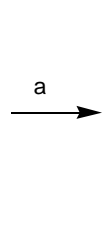<smiles>Cc1cc2cc(NS(=O)(=O)Cc3ccc(C(=O)NO)cc3)ccc2n(C)c1=O</smiles>

$60 \mathrm{a}$

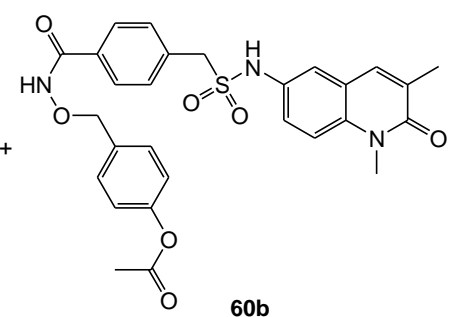

Scheme 5: Synthesis of masked hydroxamic acids 59a,b and 60a,b. Reagents and conditions: (a) HATU, DIPEA, THF, DMF. 


\section{Conclusion}

HDACs and bromodomains represent interesting epigenetic targets whose deregulation is linked to different disorders. The current work was initiated based on promising results of the combination therapy of HDAC and bromodomain inhibitors, assuming that a dual target inhibitor could achieve superior activity to the single agents. We used previously developed selective HDAC8 inhibitors as starting points and modified the cap group to achieve simultaneous HDAC8 and BRPF1 inhibition. Two dual HDAC8/BRPF1 nanomolar inhibitors (23a,b) were identified. In vitro assays and modelling studies showed that small modifications of the linker are not tolerated, especially for the BRPF1 inhibition. Since HDAC6 is in the scope of this work, we took advantage of the structural differences between different HDAC isoforms to achieve the dual HDAC6/BRPF1 inhibitor 37. Further attempts to enhance HDAC6 activity abolished the BRPF1 activity emphasizing the limited available space to optimize these dual inhibitors. The promising in vitro enzymatic results of the developed dual target inhibitors were not translated into cellular activity against AML cell lines, while the corresponding esters, which served as HDAC negative controls with only BRPF1 activity, showed a modest effect. Therefore, we assumed that the poor permeability of the hydroxamic acid is the reason for the lack of cellular activity. Indeed, western blot experiments showed a very weak acetylation of $\alpha$-tubulin, substantiating the lack of cellular HDAC6 activity of the tested compounds. In an attempt to enhance the cellular effect of the dual target inhibitors, some masked hydroxamic acids were synthesized as potential prodrugs. However, no improvement in the antiproliferative effect could be observed. Reasons for that could be the known limited cell permeability and short half-life of hydroxamic acids due to fast metabolization. One prospective modification of the developed dual inhibitors could be a replacement of the hydroxamic acid moiety by more stable and permeable zinc binding groups. It would be interesting to investigate if this modification could achieve a balance between activities on both targets and confer cellular activity. 


\section{$\underline{\text { 4. Experimental protocols }}$}

\subsection{Chemistry}

\subsubsection{General}

All materials and reagents were purchased from Sigma-Aldrich Co. Ltd. and abcr GmbH. All solvents were analytically pure and dried before use. Thin layer chromatography was carried out on aluminum sheets coated with silica gel 60 F254 (Merck, Darmstadt, Germany). For column chromatography under normal pressure silica gel $60(0.036-0.200 \mathrm{~mm})$ was used.

Final compounds were confirmed to be of $>95 \%$ purity based on HPLC. Purity was measured by UV absorbance at $254 \mathrm{~nm}$. The HPLC consists of an XTerra RP18 column $(3.5 \mu \mathrm{m}, 3.9 \mathrm{~mm} \times 100$ $\mathrm{mm}$ ) from the manufacturer Waters (Milford, MA, USA) and two LC-10AD pumps, a SPD-M10A VP PDA detector, and a SIL-HT autosampler, all from the manufacturer Shimadzu (Kyoto, Japan). For preparative tasks a XTerra RP18 column $(7 \mu \mathrm{m}, 19 \mathrm{~mm} \times 150 \mathrm{~mm})$ from the manufacturer Waters (Milford, MA, USA) and two LC-20AD pumps were used. The mobile phase was in all cases a gradient of methanol/ water (starting at $95 \%$ water going to $5 \%$ water).

Mass spectrometry analyses were performed with a Finnigan MAT710C (Thermo Separation Products, San Jose, CA, USA) for the ESIMS spectra and with a LTQ (linear ion trap) Orbitrap XL hybrid mass spectrometer (Thermo Fisher Scientific, Bremen, Germany) for the HRMS-ESI (high resolution mass spectrometry) spectra. For the HRMS analyses the signal for the isotopes with the highest prevalence was given and calculated $\left({ }^{35} \mathrm{Cl},{ }^{79} \mathrm{Br}\right)$.

${ }^{1} \mathrm{H}$ NMR and ${ }^{13} \mathrm{C}$ NMR spectra were taken on a Varian Inova 500 using deuterated chloroform and deuterated DMSO as solvent. Chemical shifts are referenced to the residual solvent signals. The following abbreviations and formulas for solvents and reagents were used: ethyl acetate (EtOAc), dimethylformamide (DMF), dimethylsulfoxide (DMSO), methanol $(\mathrm{MeOH})$, tetrahydrofuran (THF), chloroform $\left(\mathrm{CHCl}_{3}\right)$, water $\left(\mathrm{H}_{2} \mathrm{O}\right)$, dichloromethane $\left(\mathrm{CH}_{2} \mathrm{Cl}_{2}\right)$, N,N-diisopropylethylamine (DIPEA), trimethylamine (TEA), hydrochloric acid ( $\mathrm{HCl})$ and trifluoroacetic acid (TFA).

4.1.2. General method for the synthesis of methyl 3-[(1,3-dimethyl-2-oxo-1,2-dihydroquinolin-6yl)carbamoyl]-4-substitutedbenzoates (15a-b)

The appropriate 5-methoxycarbonyl-2-substitutedbenzoic acid 9a-b (3 mmol), DMF (one drop) and oxalyl chloride ( $4 \mathrm{mmol}$ ) were stirred in $\mathrm{CH}_{2} \mathrm{Cl}_{2}$ at room temperature for $3 \mathrm{~h}$. The mixture was then added dropwise to a solution of 6-amino-1,3-dimethylquinolin-2-(1H)-one $(\mathbf{5} ; 3 \mathrm{mmol})$ and DIPEA ( $8 \mathrm{mmol}$ ) in $\mathrm{CH}_{2} \mathrm{Cl}_{2}$, and stirring was continued for another $2 \mathrm{~h}$ at room temperature. The reaction mixture was washed with a saturated aqueous solution of ammonium chloride and brine. The organic layer was dried over anhydrous sodium sulfate, filtered, and concentrated in vacuo. The residue was purified using column chromatography $\left(\mathrm{CHCl}_{3}: \mathrm{MeOH}, 100: 0-99: 1\right)$.

Detailed characterization data of the compounds are provided in the supporting information.

4.1.3. General method for the synthesis of methyl 3-[(1,3-dimethyl-2-oxo-1,2-dihydroquinolin-6ylamino)methyl]-4-substitutedbenzoates (18a-b)

A mixture of the appropriate 4-substituted-3-formylbenzoate 8a-b $(1.2 \mathrm{mmol})$ and 6-amino-1,3dimethylquinolin-2-(1H)-one $(5 ; 1 \mathrm{mmol})$ was dissolved in toluene, and the reaction mixture was refluxed for $2 \mathrm{~h}$ using a dean stark apparatus. The solvent was then evaporated under reduced pressure, and the crude product was dissolved in $\mathrm{CH}_{2} \mathrm{Cl}_{2}$ and cooled to $0{ }^{\circ} \mathrm{C}$. Then sodium triacetoxyborohydride ( $4 \mathrm{mmol}$ ) was added and the reaction mixture was stirred overnight at room temperature. The reaction was quenched by adding $\mathrm{H}_{2} \mathrm{O}$, and the $\mathrm{pH}$ was adjusted to 5 with aqueous potassium bicarbonate solution. The mixture was extracted with EtOAc, and the organic layer was 
evaporated under vacuum. The products were purified by column chromatography $\left(\mathrm{CHCl}_{3}: \mathrm{MeOH}\right.$, 100:0-99:1).

Detailed characterization data of the compounds are provided in the supporting information.

4.1.4. General method for the ef-synthesis of methyl 3(or 4)-[(1,3-dimethyl-2-oxo-1,2dihydroquinolin-6-yl)sulfamoyl]-4-substitutedbenzoates (21 and 35) and methyl 3(or 4)-\{[(1,3dimethyl-2-oxo-1,2-dihydroquinolin-6-yl)sulfamoyl]methyl \}-4-substitutedbenzoates (42a-b) and $(49 a-b)$

To a solution of 6-amino-1,3-dimethylquinolin-2-(1H)-one $(\mathbf{5} ; 1 \mathrm{mmol})$ in pyridine was added the appropriate methyl chlorosulfonylbenzoate or methyl (chlorosulfonylmethyl)benzoate 14, 34, 14a-b or 48a-b $(1 \mathrm{mmol})$, and the reaction was stirred at room temperature overnight. The solvent was then removed under vacuum, and the residue obtained was dissolved in EtOAc and washed successively with aqueous $1 \mathrm{M} \mathrm{HCl}, 1 \mathrm{M}$ copper sulfate and brine solutions. The organic layer was dried over anhydrous sodium sulfate, filtered, and concentrated in vacuo. The residue was purified using column chromatography $\left(\mathrm{CHCl}_{3}: \mathrm{MeOH}, 100: 0-99: 1\right)$.

Detailed characterization data of the compounds are provided in the supporting information.

\subsubsection{General method for the synthesis of carboxylic acids $\mathbf{1 6 a - b}, \mathbf{1 9 a}-\mathbf{b}, \mathbf{2 2 a}-\mathbf{b}, \mathbf{3 6}, \mathbf{4 3 a}-\mathbf{b}$ and} 50a-b

The appropriate methyl esters 15a-b, 18a-b, 21, 35, 42a-b or 49a-b (1 mmol) was dissolved in $\mathrm{MeOH}$ followed by the addition of aqueous solution of sodium carbonate $(10 \mathrm{mmol})$ and the mixture was stirred under reflux for 2-4 h until complete hydrolysis of the ester. $\mathrm{MeOH}$ was then evaporated and the reaction was neutralized with aqueous solution of $1 \mathrm{M} \mathrm{HCl}$ until $\mathrm{pH}$. The liberated free acid was extracted with a mixture of EtOAc and THF, and the extract was dried over sodium sulfate and evaporated under reduced pressure. The product required no further purification.

Compound 22b was prepared directly from 6-amino-1,3-dimethylquinolin-2-(1H)-one and methyl 4-chloro-3-chlorosulfonylbenzoate using the procedure described in 4.1.4.

Detailed characterization data of the compounds are provided in the supporting information.

4.1.6. General method for the of synthesis of hydroxamic acids 17a-b, 20a-b, 23a-b, 37, 44a-b and 51a-b

The appropriate carboxylic acid 16a-b, 19a-b, 22a-b, 36, 43a-b and 50a-b (1 mmol) was dissolved in dry THF, followed by the addition of PyBOP $(1.5 \mathrm{mmol})$ and DIPEA ( $3 \mathrm{mmol})$. The mixture was stirred for $15 \mathrm{~min}$, then $\mathrm{NH}_{2} \mathrm{OTHP}(1.2 \mathrm{mmol})$ was added and the reaction mixture was stirred at room temperature for 2-4 h. The solvent was evaporated under vacuum and the mixture was dissolved in EtOAc $(50 \mathrm{ml})$ and washed with $1 \mathrm{M}$ sodium carbonate solution and brine. The organic layer was evaporated under vacuum and the product was purified by column chromatography $\left(\mathrm{CHCl}_{3} / \mathrm{MeOH} / \mathrm{TEA}\right.$, 99:0.95:0.05).

The obtained product was dissolved in THF and a catalytic amount of diluted $\mathrm{HCl}$ was added. The mixture was stirred at room temperature overnight. The reaction was controlled by TLC. After that the solvent was evaporated under vacuum and the hydroxamic acid product was purified by column chromatography $\left(\mathrm{CHCl}_{3}\right.$ : $\mathrm{MeOH}$, TEA 95:4.95:0.05).

Detailed characterization data of the compounds are provided in the supporting information.

4.1.7. Synthesis of 3-\{4-[5-(1,3-dimethyl-2-oxo-1,2-dihydroquinolin-6-ylamino)-5oxopentyloxy] benzylamino $\}-N$-hydroxy-4-methoxybenzamide (32)

Detailed synthesis of intermediates 25-28 are provided in the supporting information. 


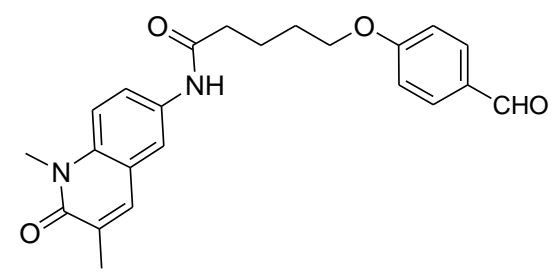

5-(4-Formylphenoxy)pentanoic acid (28; 3 mmol.), DMF (one drop) and oxalyl chloride (4 mmol) were stirred in $\mathrm{CH}_{2} \mathrm{Cl}_{2}$ at room temperature for $3 \mathrm{~h}$. The mixture was then added dropwise to a solution of 6-amino-1,3-dimethylquinolin-2-(1H)-one (5; $3 \mathrm{mmol})$ and DIPEA (8 mmol) in $\mathrm{CH}_{2} \mathrm{Cl}_{2}$, and stirring was continued for another $2 \mathrm{~h}$ at room temperature. The reaction mixture was washed with saturated aqueous solution of ammonium chloride and brine. The organic layer was dried over anhydrous sodium sulfate, filtered, and concentrated in vacuo. The residue was purified using column chromatography $\left(\mathrm{CHCl}_{3}: \mathrm{MeOH}, 100: 0-98: 2\right)$.

MS m/z: $393.20[\mathrm{M}+\mathrm{H}]^{+}$

Yield: $74 \%$

${ }^{1} \mathrm{H}$ NMR (400 MHz, DMSO) $\delta 10.00$ (s, 1H, -CO-NH-Ar), 9.84 (s, 1H, -CHO), 7.91 (d, J=2.4 Hz, $1 \mathrm{H}, \operatorname{Ar}-\boldsymbol{H}), 7.86-7.80(\mathrm{~m}, 2 \mathrm{H}, \operatorname{Ar}-\boldsymbol{H}), 7.70(\mathrm{~s}, 1 \mathrm{H}, \operatorname{Ar}-\boldsymbol{H}), 7.65(\mathrm{dd}, J=9.1,2.4 \mathrm{~Hz}, 1 \mathrm{H}, \operatorname{Ar}-\boldsymbol{H})$, $7.42(\mathrm{~d}, J=9.1 \mathrm{~Hz}, 1 \mathrm{H}, \mathrm{Ar}-\boldsymbol{H}), 7.14-7.07(\mathrm{~m}, 2 \mathrm{H}, \mathrm{Ar}-\boldsymbol{H}), 4.11$ (t, $\left.J=5.9 \mathrm{~Hz}, 2 \mathrm{H},-\mathrm{CH}_{2}-\mathrm{O}-\right), 3.60$ $\left(\mathrm{s}, 3 \mathrm{H},-\mathrm{NCH}_{3}\right), 2.39\left(\mathrm{t}, J=6.9 \mathrm{~Hz}, 2 \mathrm{H},-\mathrm{CH}_{2} \mathrm{CO}-\right), 2.10$ (d, $\left.J=1.0 \mathrm{~Hz}, 3 \mathrm{H}, \mathrm{Ar}-\mathrm{CH}_{3}\right), 1.84-1.71$ (m, $4 \mathrm{H},-\mathrm{CH}_{2}-\mathrm{C}_{2} \boldsymbol{H}_{4}-\mathrm{CH}_{2}-$ ).

4.1.7.2. 3-\{4-[5-(1,3-Dimethyl-2-oxo-1,2-dihydroquinolin-6-ylamino)-5-oxopentyloxy]benzylamino $\}-4-m e t h o x y b e n z o i c ~ a c i d ~(31)$<smiles>COc1ccc(C(=O)O)cc1NCc1ccc(OCCCCC(=O)Nc2ccc3c(c2)cc(C)c(=O)n3C)cc1</smiles>

A mixture of $\mathrm{N}$-(1,3-dimethyl-2-oxo-1,2-dihydroquinolin-6-yl)-5-(4-formylphenoxy)pentanamide (29; $1.1 \mathrm{mmol})$, 3-amino-4-methoxybenzoic acid (30;1 mmol) and TFA (2 mmol) in a (1:1) mixture of THF and EtOAc was cooled to $0{ }^{\circ} \mathrm{C}$, then sodium triacetoxyborohydride $(4 \mathrm{mmol}$ ) was added and the reaction mixture was stirred overnight at room temperature. The reaction was quenched by adding $\mathrm{H}_{2} \mathrm{O}$, and the $\mathrm{pH}$ was adjusted to 5 with aqueous potassium bicarbonate solution. The organic layer was separated and the aqueous layer was extracted with EtOAc. The organic layers were collected, dried over anhydrous sodium sulfate, filtered, and concentrated in vacuo. The residue was purified using column chromatography $\left(\mathrm{CHCl}_{3}: \mathrm{MeOH}, 100: 0-97: 3\right)$.

MS m/z: $542.82[\mathrm{M}-\mathrm{H}]$

Yield: $81 \%$

${ }^{1} \mathrm{H}$ NMR (400 MHz, DMSO) $\delta 12.26(\mathrm{~s}, 1 \mathrm{H},-\mathrm{COOH}), 9.98(\mathrm{~s}, 1 \mathrm{H},-\mathrm{CO}-\mathrm{NH}-\mathrm{Ar}), 7.91$ (d, $J=2.2$ $\mathrm{Hz}, 1 \mathrm{H}, \operatorname{Ar}-\boldsymbol{H}), 7.71(\mathrm{~s}, 1 \mathrm{H}, \operatorname{Ar}-\boldsymbol{H}), 7.65(\mathrm{dd}, J=9.1,2.3 \mathrm{~Hz}, 1 \mathrm{H}, \operatorname{Ar}-\boldsymbol{H}), 7.42(\mathrm{~d}, J=9.1 \mathrm{~Hz}, 1 \mathrm{H}$, $\operatorname{Ar}-\boldsymbol{H}), 7.25-7.16(\mathrm{~m}, 3 \mathrm{H}, \mathrm{Ar}-\boldsymbol{H}), 6.95(\mathrm{~d}, J=2.0 \mathrm{~Hz}, 1 \mathrm{H}, \mathrm{Ar}-\boldsymbol{H}), 6.89-6.82(\mathrm{~m}, 3 \mathrm{H}, \mathrm{Ar}-\boldsymbol{H}), 5.59(\mathrm{t}, \boldsymbol{J}$ $\left.=6.0 \mathrm{~Hz}, 1 \mathrm{H},-\mathrm{CH}_{2}-\mathrm{NH}-\mathrm{Ar}\right), 4.24\left(\mathrm{~d}, J=5.6 \mathrm{~Hz}, 2 \mathrm{H},-\mathrm{CH}_{2}-\mathrm{NH}-\mathrm{Ar}\right), 3.98-3.91(\mathrm{~m}, 2 \mathrm{H},-\mathrm{CH}-\mathrm{O}-)$, 3.85 (s, 3H, - $\left.\mathrm{OCH}_{3}\right), 3.60$ (s, 3H, - $\left.\mathrm{NCH}_{3}\right), 2.40-2.34$ (m, 2H, - $\left.\boldsymbol{C H}_{2} \mathrm{CO}-\right), 2.10$ (3H, Ar-CH $), 1.74$ (m, $4 \mathrm{H},-\mathrm{CH}_{2}-\mathrm{C}_{2} \boldsymbol{H}_{4}-\mathrm{CH}_{2}-$ ).

\subsubsection{3-\{4-[5-(1,3-Dimethyl-2-oxo-1,2-dihydroquinolin-6-ylamino)-5-oxopentyloxy]-} benzylamino $-N$-hydroxy-4-methoxybenzamide (32)

This compound was prepared from 3-\{4-[5-(1,3-dimethyl-2-oxo-1,2-dihydroquinolin-6-ylamino)-5oxopentyloxy]-benzylamino -4-methoxybenzoic acid (31) according to the method described in 4.1.6. 
Detailed characterization data of the compound are provided in the supporting information.

\subsubsection{General method for the synthesis of masked hydroxamic acids 59a-b and 60a-b}

The appropriate carboxylic acids $23 \mathbf{a}$ or $\mathbf{4 4 b}(1 \mathrm{mmol}$.) were dissolved in dry THF, followed by the addition of HATU $(1.2 \mathrm{mmol})$ and DIPEA $(3 \mathrm{mmol})$. The mixture was stirred for $15 \mathrm{~min}$, then the appropriate $O$-substitutedhydroxylamine 58a-b $(1.2 \mathrm{mmol})$ was added and the reaction mixture was stirred at room temperature for $2 \mathrm{~h}$. The solvent was evaporated under vacuum and the mixture was dissolved in EtOAc and washed with aqueous sodium bicarbonate and ammonium chloride solutions then brine. The organic layer was separated, dried over anhydrous sodium sulfate, filtered and concentrated in vacuo. The residue was purified by column chromatography $\left(\mathrm{CHCl}_{3}: \mathrm{MeOH}\right.$, 100:0-99:1).

Detailed characterization data of the compounds are provided in the supporting information.

\subsection{In vitro HDAC inhibitory activity}

Recombinant human HDAC1 and -6 were purchased from BPS Biosciences. Enzyme inhibition was determined by using a published homogenous fluorescence assay [97]. The enzymes were incubated for $90 \mathrm{~min}$ at $37^{\circ} \mathrm{C}$, with the fluorogenic substrate ZMAL (Z-(Ac)Lys-AMC) in a concentration of $10.5 \mu \mathrm{M}$ and increasing concentrations of inhibitors. Fluorescence intensity was measured at an excitation wavelength of $390 \mathrm{~nm}$ and an emission wavelength of $460 \mathrm{~nm}$ in a microtiter plate reader (BMG Polarstar).

Recombinant hHDAC8 was produced by Romier et al. in Strasbourg [60]. The HDAC8 activity assay was performed according to the commercial HDAC8 Fluorometric Drug Discovery Kit [Fluor de Lys ${ }^{\circledR}-$ HDAC8, BML-KI178] corresponding to the manufacturer's instructions as described earlier [98]. The substrate was a synthesized tetrapeptide bound to aminomethylecoumarine (AMC) $\mathrm{H}_{2} \mathrm{~N}$-Arg-His-Lys(Ac)-Lys(Ac)-AMC. The enzyme was incubated for $90 \mathrm{~min}$ at $37^{\circ} \mathrm{C}$, with a substrate concentration of $50 \mu \mathrm{M}$ and increasing concentrations of inhibitors. The Stop-solution containing Trichostatin A (TSA), to stop the hHDAC8 activity, and Trypsin, to release the AMC, was added. The solution was incubated for $20 \mathrm{~min}$ at $37^{\circ} \mathrm{C}$ to develop the assay. Fluorescence intensity was measured at an excitation wavelength of $355 \mathrm{~nm}$ and an emission wavelength of 460 $\mathrm{nm}$ in a microtiter plate reader (BMG Polarstar). Detailed synthesis and characterization of the substrate are provided in the supporting information.

\subsection{Isothermal titration calorimetry (ITC)}

ITC experiments were carried out and processed as described previously [99-101] using Microcal Origin for experiment setups, NITPIC [102, 103] and SEDPHAT [104] for data evaluation, and GUSSI [105] for plotting. Ligand concentrations were between 20 and $40 \mu \mathrm{M}$ in the sample cell and BRPF1 concentrations between 200 and $400 \mu \mathrm{M}$ in the injection syringe. Images and calculations are provided in the supporting information. For the final $\mathrm{K}_{\mathrm{d}}$ BRPF1 value the P99 interval was determined.

\subsection{Cellular assays}

\subsubsection{Viability of human HEK293 cells}

HEK293 cells (DSMZ Braunschweig, ACC305) were incubated at $37{ }^{\circ} \mathrm{C}$ in a humidified incubator with $5 \% \mathrm{CO}_{2}$ in Dulbecco's modified Eagle's medium (DMEM) supplemented with 10\% FCS and $5 \mathrm{mM}$ glutamine. Cells were seeded at $1.5 \times 10^{3}$ cells per well in a 96-well cell culture plate (TPP, Switzerland). The compounds were added immediately to the medium at $50 \mu \mathrm{M}$ to determine the percentage viability. After $24 \mathrm{~h}$, AlamarBlue ${ }^{\circledR}$ reagent (Invitrogen, CA, USA) was added according to the manufacturer's instructions and incubated again for $21 \mathrm{~h}$ before samples were analyzed. 
Detection of viable cells that convert the resazurin reagent into the highly fluorescent resorufin was performed by using a FLUOstarOPTIMA microplate reader (BMG Labtec) with the following filter set: Ex $560 \mathrm{~nm} / \mathrm{Em} 590 \mathrm{~nm}$. All measurements were performed in triplicates over three independent experiments.

\subsubsection{Antiproliferative activity on acute myeloid leukemia cells THP-1 and HL60}

HL60 or THP-1 cells were diluted in 96-well tissue culture plates at a density of 5000 per well and immediately incubated with inhibitors or DMSO vehicle to a total volume of $100 \mu \mathrm{L}$. Compounds were diluted from 200x stock solutions in DMSO and were compared to DMSO vehicle only. Three replicates per concentration were used. Growth inhibition was determined using the CellTiter 96AQueous Non-Radioactive Cell Proliferation Assay according to the manufacturer's instructions. Data was plotted as absorbance units against compound concentration for pretest results or against logarithm of compound concentration using OriginPro 9. 50\% Growth inhibition $\left(\mathrm{GI}_{50}\right)$ was determined as compound concentration required to reduce the number of metabolically active cells by $50 \%$ compared to DMSO control. The assay was already described for MCF7 [106].

\subsubsection{Western blot assay in THP-1 and HL60}

HL60 or THP-1 cells were seeded in a 12-well plate at a density of $2.5 \times 10^{5}$ cells per well, and immediately incubated with different concentrations of test compounds for $4 \mathrm{~h}$. After incubation, cells were collected in Eppendorf tubes and centrifuged with $500 \mathrm{~g}$ for $5 \mathrm{~min}$ at room temperature. Cells were washed with phosphate-buffered saline and lysed in $90 \mu \mathrm{L}$ of sodium dodecyl sulfate (SDS) sample buffer (cell signaling, $62.5 \mathrm{mM}$ Tris hydrochloride (pH 6.8 at $25^{\circ} \mathrm{C}$ ), $2 \% \mathrm{w} / \mathrm{v}$ SDS, $10 \% \mathrm{v} / \mathrm{v}$ glycerol, $50 \mathrm{mM}$ dithiothreitol, $0.01 \%$ bromophenol blue). After sonicating for $5 \mathrm{~min}$, to shear DNA and reduce sample viscosity, the samples were heated to $95{ }^{\circ} \mathrm{C}$ for $1 \mathrm{~min}$. Cell extracts were used directly for SDS polyacrylamide gel electrophoresis (PAGE) or kept frozen at $-20{ }^{\circ} \mathrm{C}$ until usage. For the SDS-PAGE, an amount of $7 \mu \mathrm{L}$ of cell extracts was loaded onto a $12.5 \%$ SDS gel and run at $160 \mathrm{~V}$ followed by the transfer to a nitrocellulose membrane via western blotting for antibody-based detection. After transfer, the nonspecific binding was blocked by incubating the membrane in $25 \mathrm{~mL}$ of blocking buffer [5\% nonfat dry milk in Tris buffered saline with $0.1 \%$ Tween 20 (TBS-T)] for $1 \mathrm{~h}$ at room temperature or at $4{ }^{\circ} \mathrm{C}$ overnight. After washing the membrane three times for 5 min with TBS-T, the primary antibody [antiacetylated $\alpha$-tubulin (Sigma-Aldrich T7451-200UL, 1:1000)] was added in 3\% milk in TBS-T for $3 \mathrm{~h}$ at room temperature or overnight at $4{ }^{\circ} \mathrm{C}$. Before exposing the membrane with the secondary antibody, it was washed again three times for 5 min with TBS-T to remove an unbound primary antibody. The secondary antibody antimouse-IgG-HRP (Sigma-Aldrich, 1:2000) was added in 3\% milk in TBS-T at room temperature for $1 \mathrm{~h}$. Afterward, the membrane was washed again. The detection was performed via enhanced chemiluminescence (ECL Prime) after incubation for $5 \mathrm{~min}$ in the dark with a FUSION-SL (PEQLAB) and the FUSION-CAPT software. After detection of acetylated tubulin, the whole procedure was repeated with the primary antibody antiacetyl-histone H3 (Millipore 06.599, 1:2000) and the secondary antibody anti-rabbit IgG-HRP (Sigma-Aldrich, 1:5000) to detect the acetylation of histone $\mathrm{H} 3$ and again with the primary antibody antiGAPDH (Sigma-Aldrich 69545-200UL, 1:5000) and the secondary antibody antirabbit IgGHRP (Sigma-Aldrich, 1:10 000) to control the loading amount.

\subsection{Docking and molecular dynamics simulations}

\subsubsection{Docking into HDAC8}


The crystal structure of an HDAC8/inhibitor complex (PDB ID 2V5X) was downloaded from Protein Data Bank [107] and only chain A was retained. Protein preparation was done using Schrödinger's Protein Preparation Wizard (Schrödinger Suite 2017-1: Protein Preparation Wizard; Epik, Schrödinger, LLC, New York, NY, 2016; Impact, Schrödinger, LLC, New York, NY, 2016; Prime, Schrödinger, LLC, New York, NY, 2017) by adding hydrogen atoms, assigning protonation states and minimizing the protein. Solvent molecules were removed except for two conserved water molecules: $\mathrm{HOH} 2061$ and $\mathrm{HOH} 2152$. Hydrogen bond networks, amino acid residues protonation states and tautomers were optimized, and the complex was finally subjected to energy minimization using the OPLS-2005 force field using the default settings. Receptor grids were generated using default settings by assigning the cocrystallized ligand as the center of the grid.

Ligands were first prepared using LigPrep (Schrödinger Release 2017-1: LigPrep, Schrödinger, LLC, New York, NY, 2017) were the hydroxamic acids were kept in the neutral forms and energy minimized using the OPLS2005 force field. Twenty conformers for each ligand were subsequently generated using ConfGen (Schrödinger Release 2017-1: ConfGen, Schrödinger, LLC, New York, NY, 2017).

Molecular docking was performed using Glide (Schrödinger Release 2017-1: Glide, Schrödinger, LLC, New York, NY, 2017) in the Standard Precision mode. Default settings without any constraints were used, the number of docking poses for post-docking minimization per ligand was increased to 20 and the maximal number of output poses per ligand was set to 2 .

\subsubsection{Docking into HDAC6}

The crystal structure HDAC6/trichostatin A complex (PDB ID 5EDU) was downloaded from the Protein Data Bank and only chain A was kept. Since the crystal structure was resolved without water molecules in the binding site, we chose to insert the crucial water molecules by superposing with the crystal structures of the homologous DrHDAC6 in complex with HPOB (PDB ID 5EF7). Altogether, four water molecules $(\mathrm{HOH} 921,990,999$, and 1011) together with the cocrystallized ligand HPOP were taken from chain A of the crystal structure of DrHDAC6 (PDB ID 5EF7). Further protein preparation was performed as described for HDAC8; the ligand was however kept in the deprotonated hydroxamate form. Ligands were generated in the hydroxamate form and further prepared using Ligprep and ConfGen as previously described.

Molecular docking was performed using Glide in the Standard Precision mode using the same settings as with HDAC8.

\subsubsection{Docking into BRPF1}

The crystal structure BRPF1/NI-57 complex (PDB ID 5MYG) was downloaded from the Protein Data Bank, and only chain $\mathrm{C}$ together with the ligand and four water molecules (HOH 906, 907, 910, and 911) were kept. The complex was prepared using Schrödinger's Protein Preparation Wizard as described for HDAC8. Ligands were prepared using LigPrep and 20 conformers were generated using ConfGen as previously described. Docking was finally performed using Glide in the Standard Precision mode using the same setting as described for HDAC8. The applied setting was able to reproduce the binding mode of NI-57 in BRPF1 (RMSD $<1 \AA$ ).

\subsubsection{Molecular dynamics simulation}

Initial coordinates of the BRPF1/ligand complexes were taken from the obtained docking poses described above. MD simulations were performed using Amber16 package (AMBER 2016, UCSF, San Francisco, California, USA, 2016). Force field parameters for the ligands were assigned using the Antechamber package and AM1-BCC atomic charges [108, 109]. The complex structure was 
combined using the TLeap module, where the ff14SB force field $[110,111]$ and the General Amber Force Field (GAFF2) [112] were used for the parameterization of protein residues and ligand, respectively. The complex structures were solvated in an octahedral periodic box of SPC/E water molecules [113] at a margin of $10 \AA$ and the system was neutralized using $\mathrm{Na}^{+}$counter ions.

The system was first subjected to two steps of minimization: The first step involved the minimization of only the solvent atoms in 3000 iterations (first 1000 steepest descent and then 2000 conjugate gradient), while restraining the protein, ligand and conserved water molecules to their initial coordinates with a force constant of $10 \mathrm{kcal}^{*} \mathrm{~mol}^{-1} * \AA^{-2}$. In the second step, the whole system was minimized with no restraints using 4000 iterations (first 2000 steepest descent and then 2000 conjugate gradient). The system was subsequently heated to the production temperature $(300 \mathrm{~K}$ ) through 100 ps of MD simulation, while keeping the complex atoms (protein, ligand and conserved water molecules) restrained with a force constant of $10 \mathrm{kcal}^{*} \mathrm{~mol}^{-1} * \AA^{-2}$. Constant volume periodic boundary was set to equilibrate the temperature of the system by Langevin thermostat using a collision frequency of $2 \mathrm{ps}^{-1}$. The system was subsequently subjected to a pressure equilibration routine for $100 \mathrm{ps}$ at $300 \mathrm{~K}$, where a constant pressure of 1 bar was applied.

Finally, a production run of $100 \mathrm{~ns}$ with a time step of 2 fs was simulated at a constant temperature of $300 \mathrm{~K}$ using Langevin thermostat with a collision frequency of $2 \mathrm{ps}^{-1}$. Constant pressure periodic boundary was used to maintain the pressure of the system at 1 bar using isotropic position scaling with a relaxation time of 2 ps. A non-bonded cut-off distance of $10.0 \AA$ for long-range electrostatic interactions was used by applying the Particle Mesh Ewald (PME) [114] method during the temperature equilibration and MD routines. The SHAKE algorithm [115] was applied to constrain all bonds involving hydrogen. All simulations were run using PMEMD.cuda implementation in Amber16 on CUDA-enabled NVIDIA graphics processing units (GPUs).

RMSD analysis of the trajectories was performed using the CPPTRAJ module of Amber16. Plots were generated using the R package, and the videos using PYMOL.

\subsubsection{PAINS filter.}

All the herein described compounds were filtered for pan-assay interference compounds (PAINS)[116]. For this purpose, PAINS1, PAINS2 and PAINS3 filters, as implemented in Schrödinger's Canvas program, were employed. None of the compounds was flagged as PAINS.

\section{Author contribution}

Ehab Ghazy: Synthesis of all inhibitors, preparation of manuscript.

Patrik Zeyen: Carried out HDAC8 in vitro assays.

Daniel Herp: Carried out HDAC1 and 6 in vitro assays.

Karin Schmidtkunz: AML cellular assays and western blot.

Martin Hügle: Produced the recombinant BRPF1 protein and ran the ITC assay

Frank Erdmann: Carried out cytotoxicity tests on HEK293 cells.

Dina Robaa: Did all modelling studies, preparation of manuscript.

Matthias Schmidt: Did compound analytics, supervision of organic synthesis.

Elizabeth R. Morales: Produced the recombinant HDAC8 protein for in vitro testing.

Christophe Romier: Coordination of protein expression and preparation of manuscript.

Stefan Günther: Coordination of ITC assays, preparation of manuscript. 
Manfred Jung: Coordination of HDAC1\&6, AML cellular assays and western blot, preparation of manuscript.

Wolfgang Sippl: Study design, research planning, preparation of manuscript.

\section{Acknowledgment}

E.G. received his scholarship through the GERLS program from the German Academic Exchange Service (DAAD) and Ministry of higher education, Egypt. W.S. and M.J. acknowledge the funding from Deutsche Forschungsgemeinschaft (DFG Grants Ju 295/13-1, Si 846/13-1)). This work was supported by the European Regional Development Fund of the European Commission.

\section{Appendix A. Supplementary data}

Supplementary data to this article can be found online at: https://doi.org/10.1016/j.ejmech.2020.112338.

\begin{tabular}{|c|c|}
\hline \multicolumn{2}{|c|}{ Abbreviations } \\
\hline HDAC & Histone Deacetylase \\
\hline BRD & Bromodomain \\
\hline PTMs & Post-Translational Modification \\
\hline DNA & Deoxyribonucleic Acid \\
\hline HAT & Histone Acetyltransferase \\
\hline BRPF & Bromodomain and PHD Finger-Containing Protein \\
\hline FDA & U.S. Food and Drug Administration \\
\hline HSP 90 & Heat Shock Protein 90 \\
\hline BET & Bromodomain and Extra-Terminal Motif \\
\hline PDB & Protein Data Bank \\
\hline RMSD & Root-Mean-Square Deviation \\
\hline MD & Molecular Dynamics \\
\hline AML & Acute Myeloid Leukemia \\
\hline GAPDH & Glyceraldehyde 3-Phosphate Dehydrogenase \\
\hline Ac & Acetylated \\
\hline DMSO & Dimethyl Sulfoxide \\
\hline TFA & Trifluoroacetic Acid \\
\hline PyBOP & Benzotriazol-1-Yl-Oxytripyrrolidinophosphonium Hexafluorophosphate \\
\hline HATU & Hexafluorophosphate Azabenzotriazole Tetramethyl Uronium \\
\hline HPLC & High-Performance Liquid Chromatography \\
\hline UV & Ultraviolet \\
\hline ESI-MS & Electrospray Ionization Mass Spectrometry \\
\hline HRMS-ESI & High Resolution Mass Spectroscopy- Electrospray Ionization \\
\hline EtOAc & Ethyl Acetate \\
\hline DMF & Dimethylformamide \\
\hline $\mathrm{MeOH}$ & Methanol \\
\hline THF & Tetrahydrofuran \\
\hline $\mathrm{CHCl}_{3}$ & Chloroform \\
\hline $\mathrm{H}_{2} \mathrm{O}$ & Water \\
\hline $\mathrm{CH}_{2} \mathrm{Cl}_{2}$ & Dichloromethane \\
\hline DIPEA & N,N-Diisopropylethylamine \\
\hline $\mathrm{HCl}$ & Hydrochloric Acid \\
\hline TEA & Triethylamine \\
\hline
\end{tabular}




$\begin{array}{ll}\text { h } & \text { Hour } \\ \text { TLC } & \text { Thin Layer Chromatography } \\ \text { mmol } & \text { Millimole } \\ \text { Min } & \text { Minute } \\ \text { TSA } & \text { Trichostatin A } \\ \text { AMC } & \text { Aminomethylcoumarin } \\ \text { ITC } & \text { Isothermal Titration Calorimetry } \\ \text { DMEM } & \text { Dulbecco's Modified Eagle's Medium } \\ \text { SDS } & \text { Sodium Dodecyl Sulfate } \\ \text { PAGE } & \text { Polyacrylamide Gel Electrophoresis } \\ \text { TBS-T } & \text { Tris Buffered Saline With 0.1\% Tween 20 } \\ \text { ECL } & \text { Enhanced Chemiluminescence } \\ \text { GAFF2 } & \text { General Amber Force Field } \\ \text { Ps } & \text { Picosecond } \\ \text { Gpus } & \text { Graphics Processing Units } \\ \text { HEK } & \text { Human Embryonic Kidney } \\ \text { n.d. } & \text { Not Determined }\end{array}$

\section{References}

[1] G. Zhang, S. Pradhan, Mammalian epigenetic mechanisms, IUBMB Life, 66 (2014) 240-256.

[2] J. Fan, K.A. Krautkramer, J.L. Feldman, J.M. Denu, Metabolic regulation of histone posttranslational modifications, ACS Chem Biol, 10 (2015) 95-108.

[3] A.M. Arnaudo, B.A. Garcia, Proteomic characterization of novel histone post-translational modifications, Epigenetics Chromatin, 6 (2013) 24.

[4] R. Sanchez, J. Meslamani, M.M. Zhou, The bromodomain: from epigenome reader to druggable target, Biochim. Biophys. Acta, 1839 (2014) 676-685.

[5] A. Spyropoulou, C. Piperi, C. Adamopoulos, A.G. Papavassiliou, Deregulated chromatin remodeling in the pathobiology of brain tumors, Neuromolecular Med, 15 (2013) 1-24.

[6] F. Miao, I.G. Gonzalo, L. Lanting, R. Natarajan, In vivo chromatin remodeling events leading to inflammatory gene transcription under diabetic conditions, J. Biol. Chem., 279 (2004) 1809118097.

[7] B.R. Selvi, D.V. Mohankrishna, Y.B. Ostwal, T.K. Kundu, Small molecule modulators of histone acetylation and methylation: a disease perspective, Biochim. Biophys. Acta, 1799 (2010) 810-828.

[8] S.N. Khan, A.U. Khan, Role of histone acetylation in cell physiology and diseases: An update, Clin. Chim. Acta, 411 (2010) 1401-1411.

[9] S. Timmermann, H. Lehrmann, A. Polesskaya, A. Harel-Bellan, Histone acetylation and disease, Cell. Mol. Life Sci., 58 (2001) 728-736.

[10] G.A. Josling, S.A. Selvarajah, M. Petter, M.F. Duffy, The role of bromodomain proteins in regulating gene expression, Genes (Basel), 3 (2012) 320-343.

[11] E. Ferri, C. Petosa, C.E. McKenna, Bromodomains: Structure, function and pharmacology of inhibition, Biochem. Pharmacol., 106 (2016) 1-18.

[12] P. Filippakopoulos, S. Knapp, Targeting bromodomains: epigenetic readers of lysine acetylation, Nat Rev Drug Discov, 13 (2014) 337-356.

[13] F.A. Romero, A.M. Taylor, T.D. Crawford, V. Tsui, A. Cote, S. Magnuson, Disrupting AcetylLysine Recognition: Progress in the Development of Bromodomain Inhibitors, J. Med. Chem., 59 (2016) 1271-1298.

[14] S.G. Smith, M.M. Zhou, The Bromodomain: A New Target in Emerging Epigenetic Medicine, ACS Chem Biol, 11 (2016) 598-608.

[15] B.J. Klein, M.E. Lalonde, J. Cote, X.J. Yang, T.G. Kutateladze, Crosstalk between epigenetic readers regulates the MOZ/MORF HAT complexes, Epigenetics, 9 (2014) 186-193. 
[16] A. Poplawski, K. Hu, W. Lee, S. Natesan, D. Peng, S. Carlson, X. Shi, S. Balaz, J.L. Markley, K.C. Glass, Molecular insights into the recognition of N-terminal histone modifications by the BRPF1 bromodomain, J. Mol. Biol., 426 (2014) 1661-1676.

[17] H. Shima, K. Yamagata, Y. Aikawa, M. Shino, H. Koseki, H. Shimada, I. Kitabayashi, Bromodomain-PHD finger protein 1 is critical for leukemogenesis associated with MOZ-TIF2 fusion, Int. J. Hematol., 99 (2014) 21-31.

[18] E.H. Demont, P. Bamborough, C.W. Chung, P.D. Craggs, D. Fallon, L.J. Gordon, P. Grandi, C.I. Hobbs, J. Hussain, E.J. Jones, A. Le Gall, A.M. Michon, D.J. Mitchell, R.K. Prinjha, A.D. Roberts, R.J. Sheppard, R.J. Watson, 1,3-Dimethyl Benzimidazolones Are Potent, Selective Inhibitors of the BRPF1 Bromodomain, ACS Med Chem Lett, 5 (2014) 1190-1195.

[19] P. Bamborough, H.A. Barnett, I. Becher, M.J. Bird, C.W. Chung, P.D. Craggs, E.H. Demont, H. Diallo, D.J. Fallon, L.J. Gordon, P. Grandi, C.I. Hobbs, E. Hooper-Greenhill, E.J. Jones, R.P. Law, A. Le Gall, D. Lugo, A.M. Michon, D.J. Mitchell, R.K. Prinjha, R.J. Sheppard, A.J. Watson, R.J. Watson, GSK6853, a Chemical Probe for Inhibition of the BRPF1 Bromodomain, ACS Med Chem Lett, 7 (2016) 552-557.

[20] W.S. Palmer, Development of small molecule inhibitors of BRPF1 and TRIM24 bromodomains, Drug Discov Today Technol, 19 (2016) 65-71.

[21] W.S. Palmer, G. Poncet-Montange, G. Liu, A. Petrocchi, N. Reyna, G. Subramanian, J. Theroff, A. Yau, M. Kost-Alimova, J.P. Bardenhagen, E. Leo, H.E. Shepard, T.N. Tieu, X. Shi, Y. Zhan, S. Zhao, M.C. Barton, G. Draetta, C. Toniatti, P. Jones, M. Geck Do, J.N. Andersen, Structure-Guided Design of IACS-9571, a Selective High-Affinity Dual TRIM24-BRPF1 Bromodomain Inhibitor, J. Med. Chem., 59 (2016) 1440-1454.

[22] J. Bennett, O. Fedorov, C. Tallant, O. Monteiro, J. Meier, V. Gamble, P. Savitsky, G.A. Nunez-Alonso, B. Haendler, C. Rogers, P.E. Brennan, S. Muller, S. Knapp, Discovery of a Chemical Tool Inhibitor Targeting the Bromodomains of TRIM24 and BRPF, J. Med. Chem., 59 (2016) 1642-1647.

[23] L. Bouche, C.D. Christ, S. Siegel, A.E. Fernandez-Montalvan, S.J. Holton, O. Fedorov, A. Ter Laak, T. Sugawara, D. Stockigt, C. Tallant, J. Bennett, O. Monteiro, L. Diaz-Saez, P. Siejka, J. Meier, V. Putter, J. Weiske, S. Muller, K.V.M. Huber, I.V. Hartung, B. Haendler, Benzoisoquinolinediones as Potent and Selective Inhibitors of BRPF2 and TAF1/TAF1L Bromodomains, J. Med. Chem., 60 (2017) 4002-4022.

[24] N. Igoe, E.D. Bayle, O. Fedorov, C. Tallant, P. Savitsky, C. Rogers, D.R. Owen, G. Deb, T.C. Somervaille, D.M. Andrews, N. Jones, A. Cheasty, H. Ryder, P.E. Brennan, S. Muller, S. Knapp, P.V. Fish, Design of a Biased Potent Small Molecule Inhibitor of the Bromodomain and PHD Finger-Containing (BRPF) Proteins Suitable for Cellular and in Vivo Studies, J. Med. Chem., 60 (2017) 668-680.

[25] N. Igoe, E.D. Bayle, C. Tallant, O. Fedorov, J.C. Meier, P. Savitsky, C. Rogers, Y. Morias, S. Scholze, H. Boyd, D. Cunoosamy, D.M. Andrews, A. Cheasty, P.E. Brennan, S. Muller, S. Knapp, P.V. Fish, Design of a Chemical Probe for the Bromodomain and Plant Homeodomain FingerContaining (BRPF) Family of Proteins, J. Med. Chem., 60 (2017) 6998-7011.

[26] J. Zhu, A. Caflisch, Twenty Crystal Structures of Bromodomain and PHD Finger Containing Protein 1 (BRPF1)/Ligand Complexes Reveal Conserved Binding Motifs and Rare Interactions, J. Med. Chem., 59 (2016) 5555-5561.

[27] J. Zhu, C. Zhou, A. Caflisch, Structure-based discovery of selective BRPF1 bromodomain inhibitors, Eur J Med Chem, 155 (2018) 337-352.

[28] P. Bertrand, Inside HDAC with HDAC inhibitors, Eur J Med Chem, 45 (2010) 2095-2116. [29] L. Zhang, J. Zhang, Q. Jiang, L. Zhang, W. Song, Zinc binding groups for histone deacetylase inhibitors, J Enzyme Inhib Med Chem, 33 (2018) 714-721.

[30] P. Gallo, M.V. Latronico, P. Gallo, S. Grimaldi, F. Borgia, M. Todaro, P. Jones, P. Gallinari, R. De Francesco, G. Ciliberto, C. Steinkuhler, G. Esposito, G. Condorelli, Inhibition of class I 
histone deacetylase with an apicidin derivative prevents cardiac hypertrophy and failure, Cardiovasc. Res., 80 (2008) 416-424.

[31] H. Kook, J.J. Lepore, A.D. Gitler, M.M. Lu, W. Wing-Man Yung, J. Mackay, R. Zhou, V. Ferrari, P. Gruber, J.A. Epstein, Cardiac hypertrophy and histone deacetylase-dependent transcriptional repression mediated by the atypical homeodomain protein Hop, J. Clin. Invest., 112 (2003) 863-871.

[32] A. Mai, D. Rotili, S. Valente, A.G. Kazantsev, Histone deacetylase inhibitors and neurodegenerative disorders: holding the promise, Curr. Pharm. Des., 15 (2009) 3940-3957. [33] E. Soragni, C. Xu, A. Cooper, H.L. Plasterer, J.R. Rusche, J.M. Gottesfeld, Evaluation of histone deacetylase inhibitors as therapeutics for neurodegenerative diseases, Methods Mol. Biol., 793 (2011) 495-508.

[34] Y. Zhou, Q. Wang, Q. Yang, J. Tang, C. Xu, D. Gai, X. Chen, J. Chen, Histone Deacetylase 3 Inhibitor Suppresses Hepatitis C Virus Replication by Regulating Apo-A1 and LEAP-1 Expression, Virol Sin, 33 (2018) 418-428.

[35] T.D. Zaikos, M.M. Painter, N.T. Sebastian Kettinger, V.H. Terry, K.L. Collins, Class 1Selective Histone Deacetylase (HDAC) Inhibitors Enhance HIV Latency Reversal while Preserving the Activity of HDAC Isoforms Necessary for Maximal HIV Gene Expression, J. Virol., 92 (2018). [36] Y. Imai, Y. Maru, J. Tanaka, Action mechanisms of histone deacetylase inhibitors in the treatment of hematological malignancies, Cancer Sci, 107 (2016) 1543-1549.

[37] A.C. West, R.W. Johnstone, New and emerging HDAC inhibitors for cancer treatment, J. Clin. Invest., 124 (2014) 30-39.

[38] A. Suraweera, K.J. O'Byrne, D.J. Richard, Combination Therapy With Histone Deacetylase Inhibitors (HDACi) for the Treatment of Cancer: Achieving the Full Therapeutic Potential of HDACi, Frontiers in oncology, 8 (2018) 92.

[39] I. Kopljar, D.J. Gallacher, A. De Bondt, L. Cougnaud, E. Vlaminckx, I. Van den Wyngaert, H.R. Lu, Functional and Transcriptional Characterization of Histone Deacetylase InhibitorMediated Cardiac Adverse Effects in Human Induced Pluripotent Stem Cell-Derived Cardiomyocytes, Stem cells translational medicine, 5 (2016) 602-612.

[40] J. Roche, P. Bertrand, Inside HDACs with more selective HDAC inhibitors, Eur J Med Chem, 121 (2016) 451-483.

[41] J. Fraczek, T. Vanhaecke, V. Rogiers, Toxicological and metabolic considerations for histone deacetylase inhibitors, Expert Opin Drug Metab Toxicol, 9 (2013) 441-457.

[42] S. Dallavalle, C. Pisano, F. Zunino, Development and therapeutic impact of HDAC6-selective inhibitors, Biochem. Pharmacol., 84 (2012) 756-765.

[43] G.I. Aldana-Masangkay, K.M. Sakamoto, The role of HDAC6 in cancer, Journal of biomedicine \& biotechnology, 2011 (2011) 875824.

[44] K.V. Butler, J. Kalin, C. Brochier, G. Vistoli, B. Langley, A.P. Kozikowski, Rational design and simple chemistry yield a superior, neuroprotective HDAC6 inhibitor, tubastatin A, J. Am. Chem. Soc., 132 (2010) 10842-10846.

[45] C. Zhang, C.J. Chou, Metal-Free Direct Amidation of Naphthoquinones Using Hydroxamic Acids as an Amide Source: Application in the Synthesis of an HDAC6 Inhibitor, Org Lett, 18 (2016) 5512-5515.

[46] R. De Vreese, N. Van Steen, T. Verhaeghe, T. Desmet, N. Bougarne, K. De Bosscher, V. Benoy, W. Haeck, L. Van Den Bosch, M. D'Hooghe, Synthesis of benzothiophene-based hydroxamic acids as potent and selective HDAC6 inhibitors, Chem. Commun., 51 (2015) 98689871.

[47] J. Senger, J. Melesina, M. Marek, C. Romier, I. Oehme, O. Witt, W. Sippl, M. Jung, Synthesis and Biological Investigation of Oxazole Hydroxamates as Highly Selective Histone Deacetylase 6 (HDAC6) Inhibitors, J. Med. Chem., 59 (2016) 1545-1555.

[48] H.-Y. Lee, A.-C. Tsai, M.-C. Chen, P.-J. Shen, Y.-C. Cheng, C.-C. Kuo, S.-L. Pan, Y.-M. Liu, J.-F. Liu, T.-K. Yeh, J.-C. Wang, C.-Y. Chang, J.-Y. Chang, J.-P. Liou, Azaindolylsulfonamides, 
with a More Selective Inhibitory Effect on Histone Deacetylase 6 Activity, Exhibit Antitumor Activity in Colorectal Cancer HCT116 Cells, J. Med. Chem., 57 (2014) 4009-4022.

[49] Z. Yang, T. Wang, F. Wang, T. Niu, Z. Liu, X. Chen, C. Long, M. Tang, D. Cao, X. Wang, W. Xiang, Y. Yi, L. Ma, J. You, L. Chen, Discovery of Selective Histone Deacetylase 6 Inhibitors Using the Quinazoline as the Cap for the Treatment of Cancer, J. Med. Chem., 59 (2016) 1455 1470.

[50] S. Shen, M. Hadley, K. Ustinova, J. Pavlíček, T. Knox, S. Noonepalle, M.T. Tavares, C.A. Zimprich, G. Zhang, M.B. Robers, C. Barinka, A. Kozikowski, A. Villagra, Discovery of a New Isoxazole-3-hydroxamate Based Histone Deacetylase 6 Inhibitor SS-208 with Anti-tumor Activity in Syngeneic Melanoma Mouse Models, J. Med. Chem., (2019).

[51] X.X. Wang, R.Z. Wan, Z.P. Liu, Recent advances in the discovery of potent and selective HDAC6 inhibitors, Eur J Med Chem, 143 (2018) 1406-1418.

[52] C. Simões-Pires, V. Zwick, A. Nurisso, E. Schenker, P.-A. Carrupt, M. Cuendet, HDAC6 as a target for neurodegenerative diseases: what makes it different from the other HDACs?, Molecular Neurodegeneration, 8 (2013) 7.

[53] G. Li, H. Jiang, M. Chang, H. Xie, L. Hu, HDAC6 $\alpha$-tubulin deacetylase: A potential therapeutic target in neurodegenerative diseases, J. Neurol. Sci., 304 (2011) 1-8.

[54] Y. Li, D. Shin, S.H. Kwon, Histone deacetylase 6 plays a role as a distinct regulator of diverse cellular processes, The FEBS Journal, 280 (2013) 775-793.

[55] M. Brindisi, A.P. Saraswati, S. Brogi, S. Gemma, S. Butini, G. Campiani, Old but Gold:

Tracking the New Guise of Histone Deacetylase 6 (HDAC6) Enzyme as a Biomarker and Therapeutic Target in Rare Diseases, J. Med. Chem., (2019).

[56] Y. Depetter, S. Geurs, R. De Vreese, S. Goethals, E. Vandoorn, A. Laevens, J. Steenbrugge, E. Meyer, P. de Tullio, M. Bracke, M. D'Hooghe, O. De Wever, Selective pharmacological inhibitors of HDAC6 reveal biochemical activity but functional tolerance in cancer models, Int. J. Cancer, 0 (2019).

[57] K. Vogerl, N. Ong, J. Senger, D. Herp, K. Schmidtkunz, M. Marek, M. Muller, K. Bartel, T.B. Shaik, N.J. Porter, D. Robaa, D.W. Christianson, C. Romier, W. Sippl, M. Jung, F. Bracher, Synthesis and Biological Investigation of Phenothiazine-Based Benzhydroxamic Acids as Selective Histone Deacetylase 6 Inhibitors, J. Med. Chem., 62 (2019) 1138-1166.

[58] J. Li, S. Chen, R.A. Cleary, R. Wang, O.J. Gannon, E. Seto, D.D. Tang, Histone deacetylase 8 regulates cortactin deacetylation and contraction in smooth muscle tissues, Am J Physiol Cell Physiol, 307 (2014) C288-295.

[59] A. Chakrabarti, I. Oehme, O. Witt, G. Oliveira, W. Sippl, C. Romier, R.J. Pierce, M. Jung, HDAC8: a multifaceted target for therapeutic interventions, Trends Pharmacol. Sci., 36 (2015) 481492.

[60] M. Marek, T.B. Shaik, T. Heimburg, A. Chakrabarti, J. Lancelot, E. Ramos-Morales, C. Da Veiga, D. Kalinin, J. Melesina, D. Robaa, K. Schmidtkunz, T. Suzuki, R. Holl, E. Ennifar, R.J. Pierce, M. Jung, W. Sippl, C. Romier, Characterization of Histone Deacetylase 8 (HDAC8) Selective Inhibition Reveals Specific Active Site Structural and Functional Determinants, J. Med. Chem., 61 (2018) 10000-10016.

[61] C. Zhao, J. Zang, Q. Ding, E.S. Inks, W. Xu, C.J. Chou, Y. Zhang, Discovery of metasulfamoyl N-hydroxybenzamides as HDAC8 selective inhibitors, Eur J Med Chem, 150 (2018) 282-291.

[62] W.J. Huang, Y.C. Wang, S.W. Chao, C.Y. Yang, L.C. Chen, M.H. Lin, W.C. Hou, M.Y. Chen, T.L. Lee, P. Yang, C.I. Chang, Synthesis and biological evaluation of ortho-aryl Nhydroxycinnamides as potent histone deacetylase (HDAC) 8 isoform-selective inhibitors, ChemMedChem, 7 (2012) 1815-1824.

[63] O.J. Ingham, R.M. Paranal, W.B. Smith, R.A. Escobar, H. Yueh, T. Snyder, J.A. Porco, Jr., J.E. Bradner, A.B. Beeler, Development of a Potent and Selective HDAC8 Inhibitor, ACS Med Chem Lett, 7 (2016) 929-932. 
[64] T. Heimburg, F.R. Kolbinger, P. Zeyen, E. Ghazy, D. Herp, K. Schmidtkunz, J. Melesina, T.B. Shaik, F. Erdmann, M. Schmidt, C. Romier, D. Robaa, O. Witt, I. Oehme, M. Jung, W. Sippl, Structure-Based Design and Biological Characterization of Selective Histone Deacetylase 8 (HDAC8) Inhibitors with Anti-Neuroblastoma Activity, J. Med. Chem., 60 (2017) 10188-10204. [65] T. Suzuki, Y. Ota, M. Ri, M. Bando, A. Gotoh, Y. Itoh, H. Tsumoto, P.R. Tatum, T. Mizukami, H. Nakagawa, S. Iida, R. Ueda, K. Shirahige, N. Miyata, Rapid discovery of highly potent and selective inhibitors of histone deacetylase 8 using click chemistry to generate candidate libraries, J. Med. Chem., 55 (2012) 9562-9575.

[66] S. Balasubramanian, J. Ramos, W. Luo, M. Sirisawad, E. Verner, J.J. Buggy, A novel histone deacetylase 8 (HDAC8)-specific inhibitor PCI-34051 induces apoptosis in T-cell lymphomas, Leukemia, 22 (2008) 1026-1034.

[67] S.A. Amin, N. Adhikari, T. Jha, Structure-activity relationships of HDAC8 inhibitors: Nonhydroxamates as anticancer agents, Pharmacol. Res., 131 (2018) 128-142.

[68] S. Banerjee, N. Adhikari, S.A. Amin, T. Jha, Histone deacetylase 8 (HDAC8) and its inhibitors with selectivity to other isoforms: An overview, Eur J Med Chem, 164 (2019) 214-240.

[69] A.R. de Lera, A. Ganesan, Epigenetic polypharmacology: from combination therapy to multitargeted drugs, Clin Epigenetics, 8 (2016) 105.

[70] R. Schobert, B. Biersack, Multimodal HDAC Inhibitors with Improved Anticancer Activity, Curr Cancer Drug Targets, 18 (2018) 39-56.

[71] P. Ciceri, S. Muller, A. O'Mahony, O. Fedorov, P. Filippakopoulos, J.P. Hunt, E.A. Lasater, G. Pallares, S. Picaud, C. Wells, S. Martin, L.M. Wodicka, N.P. Shah, D.K. Treiber, S. Knapp, Dual kinase-bromodomain inhibitors for rationally designed polypharmacology, Nat Chem Biol, 10 (2014) 305-312.

[72] L. Chen, J.L. Yap, M. Yoshioka, M.E. Lanning, R.N. Fountain, M. Raje, J.A. Scheenstra, J.W. Strovel, S. Fletcher, BRD4 Structure-Activity Relationships of Dual PLK1 Kinase/BRD4 Bromodomain Inhibitor BI-2536, ACS Med Chem Lett, 6 (2015) 764-769.

[73] S. Liu, H.O. Yosief, L. Dai, H. Huang, G. Dhawan, X. Zhang, A.M. Muthengi, J. Roberts, D.L. Buckley, J.A. Perry, L. Wu, J.E. Bradner, J. Qi, W. Zhang, Structure-Guided Design and Development of Potent and Selective Dual Bromodomain 4 (BRD4)/Polo-like Kinase 1 (PLK1) Inhibitors, J. Med. Chem., 61 (2018) 7785-7795.

[74] J. Wang, T. Erazo, F.M. Ferguson, D.L. Buckley, N. Gomez, P. Munoz-Guardiola, N. Dieguez-Martinez, X. Deng, M. Hao, W. Massefski, O. Fedorov, N.K. Offei-Addo, P.M. Park, L. Dai, A. DiBona, K. Becht, N.D. Kim, M.R. McKeown, J.M. Roberts, J. Zhang, T. Sim, D.R. Alessi, J.E. Bradner, J.M. Lizcano, S.C. Blacklow, J. Qi, X. Xu, N.S. Gray, Structural and Atropisomeric Factors Governing the Selectivity of Pyrimido-benzodiazipinones as Inhibitors of Kinases and Bromodomains, ACS Chem Biol, 13 (2018) 2438-2448.

[75] S.J. Atkinson, P.E. Soden, D.C. Angell, M. Bantscheff, C.W. Chung, K.A. Giblin, N. Smithers, R.C. Furze, L. Gordon, G. Drewes, I. Rioja, J. Witherington, N.J. Parr, R.K. Prinjha, The structure based design of dual HDAC/BET inhibitors as novel epigenetic probes, Medchemcomm, 5 (2014) 342-351.

[76] Z. Zhang, S. Hou, H. Chen, T. Ran, F. Jiang, Y. Bian, D. Zhang, Y. Zhi, L. Wang, L. Zhang, H. Li, Y. Zhang, W. Tang, T. Lu, Y. Chen, Targeting epigenetic reader and eraser: Rational design, synthesis and in vitro evaluation of dimethylisoxazoles derivatives as BRD4/HDAC dual inhibitors, Bioorg. Med. Chem. Lett., 26 (2016) 2931-2935.

[77] S. Amemiya, T. Yamaguchi, Y. Hashimoto, T. Noguchi-Yachide, Synthesis and evaluation of novel dual BRD4/HDAC inhibitors, Bioorg. Med. Chem., 25 (2017) 3677-3684.

[78] M. Shao, L. He, L. Zheng, L. Huang, Y. Zhou, T. Wang, Y. Chen, M. Shen, F. Wang, Z. Yang, L. Chen, Structure-based design, synthesis and in vitro antiproliferative effects studies of novel dual BRD4/HDAC inhibitors, Bioorg. Med. Chem. Lett., 27 (2017) 4051-4055. 
[79] G. Cheng, Z. Wang, J. Yang, Y. Bao, Q. Xu, L. Zhao, D. Liu, Design, synthesis and biological evaluation of novel indole derivatives as potential HDAC/BRD4 dual inhibitors and anti-leukemia agents, Bioorg Chem, 84 (2019) 410-417.

[80] T. Heimburg, A. Chakrabarti, J. Lancelot, M. Marek, J. Melesina, A.T. Hauser, T.B. Shaik, S. Duclaud, D. Robaa, F. Erdmann, M. Schmidt, C. Romier, R.J. Pierce, M. Jung, W. Sippl, StructureBased Design and Synthesis of Novel Inhibitors Targeting HDAC8 from Schistosoma mansoni for the Treatment of Schistosomiasis, J. Med. Chem., 59 (2016) 2423-2435.

[81] R. De Vreese, M. D'Hooghe, Synthesis and applications of benzohydroxamic acid-based histone deacetylase inhibitors, Eur J Med Chem, 135 (2017) 174-195.

[82] B. Hackanson, L. Rimmele, M. Benkisser, M. Abdelkarim, M. Fliegauf, M. Jung, M. Lubbert, HDAC6 as a target for antileukemic drugs in acute myeloid leukemia, Leuk. Res., 36 (2012) 10551062.

[83] K.L. Durst, B. Lutterbach, T. Kummalue, A.D. Friedman, S.W. Hiebert, The inv(16) fusion protein associates with corepressors via a smooth muscle myosin heavy-chain domain, Mol. Cell. Biol., 23 (2003) 607-619.

[84] J. Qi, S. Singh, W.K. Hua, Q. Cai, S.W. Chao, L. Li, H. Liu, Y. Ho, T. McDonald, A. Lin, G. Marcucci, R. Bhatia, W.J. Huang, C.I. Chang, Y.H. Kuo, HDAC8 Inhibition Specifically Targets Inv(16) Acute Myeloid Leukemic Stem Cells by Restoring p53 Acetylation, Cell stem cell, 17 (2015) 597-610.

[85] K. King, A.T. Hauser, J. Melesina, W. Sippl, M. Jung, Carbamates as Potential Prodrugs and a New Warhead for HDAC Inhibition, Molecules, 23 (2018) 321.

[86] S. Zheng, S. Guo, Q. Zhong, C. Zhang, J. Liu, L. Yang, Q. Zhang, G. Wang, Biocompatible Boron-Containing Prodrugs of Belinostat for the Potential Treatment of Solid Tumors, ACS Med Chem Lett, 9 (2018) 149-154.

[87] S. Schlimme, A.T. Hauser, V. Carafa, R. Heinke, S. Kannan, D.A. Stolfa, S. Cellamare, A. Carotti, L. Altucci, M. Jung, W. Sippl, Carbamate prodrug concept for hydroxamate HDAC inhibitors, ChemMedChem, 6 (2011) 1193-1198.

[88] H. Seki, S. Pellett, P. Silhar, G.N. Stowe, B. Blanco, M.A. Lardy, E.A. Johnson, K.D. Janda, Synthesis/biological evaluation of hydroxamic acids and their prodrugs as inhibitors for Botulinum neurotoxin A light chain, Bioorg. Med. Chem., 22 (2014) 1208-1217.

[89] P. Silhar, L.M. Eubanks, H. Seki, S. Pellett, S. Javor, W.H. Tepp, E.A. Johnson, K.D. Janda, Targeting botulinum A cellular toxicity: a prodrug approach, J. Med. Chem., 56 (2013) 7870-7879. [90] Y. Liao, L. Xu, S. Ou, H. Edwards, D. Luedtke, Y. Ge, Z. Qin, H2O2/Peroxynitrite-Activated Hydroxamic Acid HDAC Inhibitor Prodrugs Show Antileukemic Activities against AML Cells, ACS Med Chem Lett, 9 (2018) 635-640.

[91] R. Rais, J. Vavra, T. Tichy, R.P. Dash, A.J. Gadiano, L. Tenora, L. Monincova, C. Barinka, J. Alt, S.C. Zimmermann, C.E. Slusher, Y. Wu, K. Wozniak, P. Majer, T. Tsukamoto, B.S. Slusher, Discovery of a para-Acetoxy-benzyl Ester Prodrug of a Hydroxamate-Based Glutamate Carboxypeptidase II Inhibitor as Oral Therapy for Neuropathic Pain, J. Med. Chem., 60 (2017) 7799-7809.

[92] D. Cantillo, M.M. Moghaddam, C.O. Kappe, Hydrazine-mediated reduction of nitro and azide functionalities catalyzed by highly active and reusable magnetic iron oxide nanocrystals, J. Org. Chem., 78 (2013) 4530-4542.

[93] K. Hada, A. Suda, K. Asoh, T. Tsukuda, M. Hasegawa, Y. Sato, K. Ogawa, S. Kuramoto, Y. Aoki, N. Shimma, T. Ishikawa, H. Koyano, Angiogenesis inhibitors identified by cell-based highthroughput screening: synthesis, structure-activity relationships and biological evaluation of 3-[(E)styryl]benzamides that specifically inhibit endothelial cell proliferation, Bioorg. Med. Chem., 20 (2012) 1442-1460.

[94] Y. Jiao, B.T. Xin, Y. Zhang, J. Wu, X. Lu, Y. Zheng, W. Tang, X. Zhou, Design, synthesis and evaluation of novel 2-(1H-imidazol-2-yl) pyridine Sorafenib derivatives as potential BRAF inhibitors and anti-tumor agents, Eur J Med Chem, 90 (2015) 170-183. 
[95] Organikum: organisch-chemisches Grundpraktikum, VEB Deutscher Verlag der Wissenschaften, 1986.

[96] M. McLaughlin, M. Palucki, I.W. Davies, Efficient access to azaindoles and indoles, Org Lett, 8 (2006) 3307-3310.

[97] D.A. Stolfa, A. Stefanachi, J.M. Gajer, A. Nebbioso, L. Altucci, S. Cellamare, M. Jung, A. Carotti, Design, Synthesis, and Biological Evaluation of 2-Aminobenzanilide Derivatives as Potent and Selective HDAC Inhibitors, ChemMedChem, 7 (2012) 1256-1266.

[98] M. Marek, S. Kannan, A.T. Hauser, M. Moraes Mourao, S. Caby, V. Cura, D.A. Stolfa, K. Schmidtkunz, J. Lancelot, L. Andrade, J.P. Renaud, G. Oliveira, W. Sippl, M. Jung, J. Cavarelli, R.J. Pierce, C. Romier, Structural basis for the inhibition of histone deacetylase 8 (HDAC8), a key epigenetic player in the blood fluke Schistosoma mansoni, PLoS Pathog, 9 (2013) e1003645. [99] X. Lucas, D. Wohlwend, M. Hugle, K. Schmidtkunz, S. Gerhardt, R. Schule, M. Jung, O. Einsle, S. Gunther, 4-Acyl pyrroles: mimicking acetylated lysines in histone code reading, Angew. Chem. Int. Ed. Engl., 52 (2013) 14055-14059.

[100] M. Hugle, X. Lucas, G. Weitzel, D. Ostrovskyi, B. Breit, S. Gerhardt, O. Einsle, S. Gunther, D. Wohlwend, 4-Acyl Pyrrole Derivatives Yield Novel Vectors for Designing Inhibitors of the Acetyl-Lysine Recognition Site of BRD4(1), J. Med. Chem., 59 (2016) 1518-1530.

[101] M. Hugle, X. Lucas, D. Ostrovskyi, P. Regenass, S. Gerhardt, O. Einsle, M. Hau, M. Jung, B. Breit, S. Gunther, D. Wohlwend, Beyond the BET Family: Targeting CBP/p300 with 4-Acyl Pyrroles, Angew. Chem. Int. Ed. Engl., 56 (2017) 12476-12480.

[102] S. Keller, C. Vargas, H. Zhao, G. Piszczek, C.A. Brautigam, P. Schuck, High-precision isothermal titration calorimetry with automated peak-shape analysis, Anal. Chem., 84 (2012) 50665073.

[103] C.A. Brautigam, H.Y. Zhao, C. Vargas, S. Keller, P. Schuck, Integration and global analysis of isothermal titration calorimetry data for studying macromolecular interactions, Nature Protocols, 11 (2016) 882-894.

[104] J.C. Houtman, P.H. Brown, B. Bowden, H. Yamaguchi, E. Appella, L.E. Samelson, P. Schuck, Studying multisite binary and ternary protein interactions by global analysis of isothermal titration calorimetry data in SEDPHAT: application to adaptor protein complexes in cell signaling, Protein Sci., 16 (2007) 30-42.

[105] C.A. Brautigam, Chapter Five - Calculations and Publication-Quality Illustrations for Analytical Ultracentrifugation Data, in: J.L. Cole (Ed.) Methods Enzymol., Academic Press, 2015, pp. 109-133.

[106] S.D. Furdas, S. Shekfeh, E.M. Bissinger, J.M. Wagner, S. Schlimme, V. Valkov, M. Hendzel, M. Jung, W. Sippl, Synthesis and biological testing of novel pyridoisothiazolones as histone acetyltransferase inhibitors, Bioorg. Med. Chem., 19 (2011) 3678-3689.

[107] H.M. Berman, J. Westbrook, Z. Feng, G. Gilliland, T.N. Bhat, H. Weissig, I.N. Shindyalov, P.E. Bourne, The Protein Data Bank, Nucleic Acids Res, 28 (2000) 235-242.

[108] A. Jakalian, B.L. Bush, D.B. Jack, C.I. Bayly, Fast, efficient generation of high-quality atomic Charges. AM1-BCC model: I. Method, J. Comput. Chem., 21 (2000) 132-146.

[109] A. Jakalian, D.B. Jack, C.I. Bayly, Fast, efficient generation of high-quality atomic charges. AM1-BCC model: II. Parameterization and validation, J Comput Chem, 23 (2002) 1623-1641. [110] V. Hornak, R. Abel, A. Okur, B. Strockbine, A. Roitberg, C. Simmerling, Comparison of multiple Amber force fields and development of improved protein backbone parameters, Proteins, 65 (2006) 712-725.

[111] J.A. Maier, C. Martinez, K. Kasavajhala, L. Wickstrom, K.E. Hauser, C. Simmerling, ff14SB: Improving the Accuracy of Protein Side Chain and Backbone Parameters from ff99SB, J Chem Theory Comput, 11 (2015) 3696-3713.

[112] J.M. Wang, R.M. Wolf, J.W. Caldwell, P.A. Kollman, D.A. Case, Development and testing of a general amber force field, J. Comput. Chem., 25 (2004) 1157-1174. 
[113] H.J.C. Berendsen, J.R. Grigera, T.P. Straatsma, The Missing Term in Effective Pair Potentials, J. Phys. Chem., 91 (1987) 6269-6271.

[114] T. Darden, D. York, L. Pedersen, Particle Mesh Ewald - an N.Log(N) Method for Ewald Sums in Large Systems, J. Chem. Phys., 98 (1993) 10089-10092.

[115] J.P. Ryckaert, G. Ciccotti, H.J.C. Berendsen, Numerical-Integration of Cartesian Equations of Motion of a System with Constraints - Molecular-Dynamics of N-Alkanes, J Comput Phys, 23 (1977) 327-341.

[116] J.B. Baell, G.A. Holloway, New substructure filters for removal of pan assay interference compounds (PAINS) from screening libraries and for their exclusion in bioassays, J Med Chem, 53 (2010) 2719-2740. 